Review

\title{
Potential role of signal transducer and activator of transcription (STAT)3 signaling pathway in inflammation, survival, proliferation and invasion of hepatocellular carcinoma
}

\author{
Aruljothi Subramaniam ${ }^{\text {a,b,1 }}$, Muthu K. Shanmugam ${ }^{\text {a, } 1}$, Ekambaram Perumal ${ }^{\text {b }}$, Feng Li ${ }^{\text {a }}$, \\ Alamelu Nachiyappan ${ }^{a}$, Xiaoyun Dai a , Shivananju Nanjunda Swamy ${ }^{\text {c}}$, Kwang Seok Ahn ${ }^{\mathrm{d}}$, \\ Alan Prem Kumar a,e,f,g, Benny K.H. Tan ${ }^{\text {a }}$, Kam Man Hui ${ }^{\text {h,* }}$, Gautam Sethi ${ }^{\text {a,e,** }}$ \\ a Department of Pharmacology, Yong Loo Lin School of Medicine, National University of Singapore, Singapore 117597 \\ ${ }^{\mathrm{b}}$ Molecular Toxicology Lab, Department of Biotechnology, Bharathiar University, Coimbatore 641046, Tamil Nadu, India \\ c Department of Biotechnology, Sri Jayachamarajendra college of Engineering, JSS Technical Institutions Campus, Mysore 570006 Karnataka, India \\ d Kyung Hee University, College of Oriental Medicine, Seoul 130-701, Republic of Korea \\ e Cancer Science Institute of Singapore, National University of Singapore, Centre for Translational Medicine, 14 Medical Drive, Singapore 117599 \\ ${ }^{f}$ School of Biomedical Sciences, Faculty of Health Sciences, Curtin University, Western Australia \\ g Department of Biological Sciences, University of North Texas, Denton, Texas, USA \\ ${ }^{\mathrm{h}}$ Division of Cellular and Molecular Research, Humphrey Oei Institute of Cancer Research, National Cancer Centre, Singapore 169610
}

\section{A R T I C L E I N F O}

\section{Article history}

Received 20 July 2012

Received in revised form 18 October 2012

Accepted 21 October 2012

Available online 26 October 2012

\section{Keywords:}

Hepatocellular carcinoma

STAT3

JAKs

Proliferation

Apoptosis

Invasion

\begin{abstract}
A B S T R A C T
Hepatocellular carcinoma (HCC) is one of the most lethal malignancies, and is also the fourth most common cancer worldwide with around 700,000 new cases each year. Currently, first line chemotherapeutic drugs used for HCC include fluorouracil, cisplatin, doxorubicin, paclitaxel and mitomycin, but most of these are non-selective cytotoxic molecules with significant side effects. Sorafenib is the only approved targeted therapy by the U.S. Food and Drug Administration for HCC treatment, but patients suffer from various kinds of adverse effects, including hypertension. The signal-transducer-and-activator-of-transcription 3 (STAT3) protein, one of the members of STATs transcription factor family, has been implicated in signal transduction by different cytokines, growth factors and oncogenes. In normal cells, STAT3 activation is tightly controlled to prevent dysregulated gene transcription, whereas constitutively activated STAT3 plays an important role in tumorigenesis through the upregulation of genes involved in anti-apoptosis, proliferation and angiogenesis. Thus, pharmacologically safe and effective agents that can block STAT3 activation have the potential both for the prevention and treatment of HCC. In the present review, we discuss the possible role of STAT3 signaling cascade and its interacting partners in the initiation of HCC and also analyze the role of various STAT3 regulated genes in HCC progression, inflammation, survival, invasion and angiogenesis.
\end{abstract}

(c) 2012 Elsevier B.V. All rights reserved.

\section{Contents}

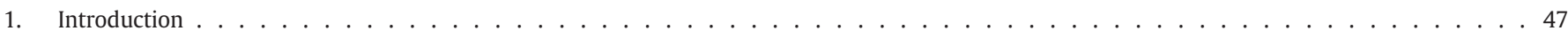

2. Role of STAT signaling pathway in the development of HCC . . . . . . . . . . . . . . . . . . . . . . . . . . . 47

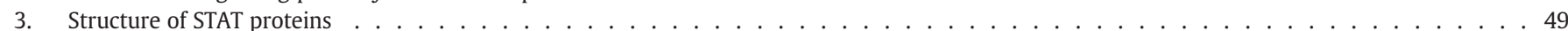

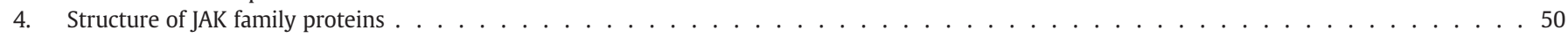

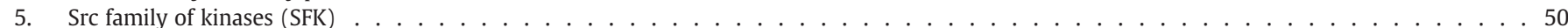

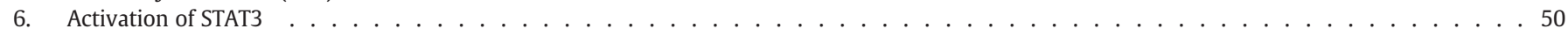

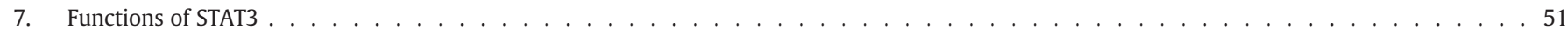

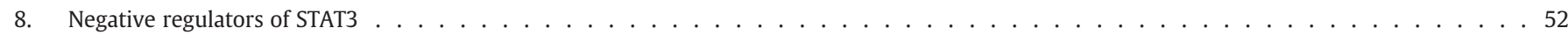

\footnotetext{
* Corresponding author. Tel.: +65 64368337; fax: +65 62263843.

** Corresponding author at: Department of Pharmacology, Yong Loo Lin School of Medicine, Cancer Science Institute of Singapore, National University of Singapore, Singapore 117597. Tel.: + 65 65163267; fax: + 6568737690 .

E-mail addresses: cmrhkm@nccs.com.sg (K.M. Hui), phcgs@nus.edu.sg (G. Sethi).

${ }^{1}$ Both authors contributed equally to this work.
} 


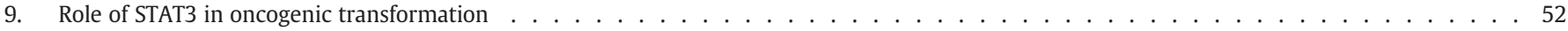

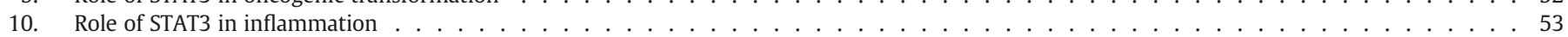

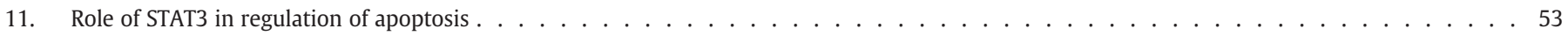

12. Role of STAT3 in cell cycle progression . . . . . . . . . . . . . . . . . . . . . . . . . . . . . . . 54

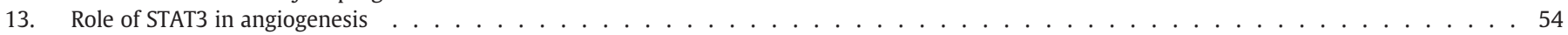

14. Role of STAT3 in cellular invasion . . . . . . . . . . . . . . . . . . . . . . . . . . . . . . 55

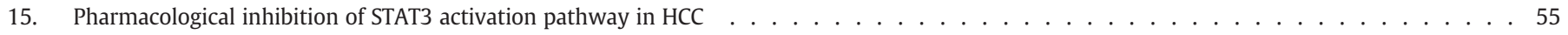

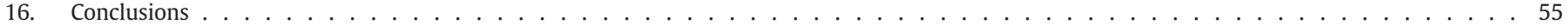

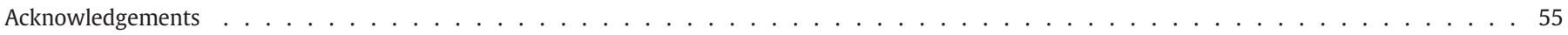

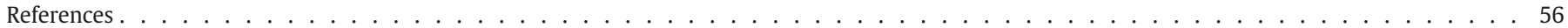

\section{Introduction}

The liver is the central organ for xenobiotic metabolism and executes several key biological functions to maintain homeostasis and health. These activities include production of proteins and hormones, detoxification of foreign chemicals, as well as glucose and lipid metabolism [1]. There are four major types of liver diseases that severely affect liver health [2]. These are (1) liver cirrhosis, (2) fatty liver, (3) virus-induced hepatitis and (4) liver cancer. Hepatitis and liver cancer have been considered as the most serious global public health problems [3-5]. Hepatocellular carcinoma (HCC), accounts for $>90 \%$ of all primary liver cancers and is the fifth most common and aggressive malignancy worldwide and the third cause of global liver cancer mortality [6-8]. It accounts for approximately one million deaths each year [9] with median survival duration of 7 to 8 months from the time of diagnosis [10]. The major risk factors for HCC development include cirrhosis, hepatitis, infections with chronic hepatitis B (HBV) or $\mathrm{C}(\mathrm{HCV})$ viral infections and environmental factors like aflatoxin exposure and alcohol or tobacco consumption [2,11,12]. For example, liver cirrhosis causes functional abnormalities that are characterized by serum albumin level that is lower than $4 \mathrm{~g} \mid \mathrm{dl}$, increased prothrombin time and persistently high serum alanine amino transferase (ALT) levels and predisposes patients to the increased risk of HCC [2]. Similarly, chronic hepatitis caused by HBV or HCV viral infections can result in death of hepatocytes with accompanying inflammatory cell infiltration. Virus-infected hepatocytes can be destroyed by host immune cells or by potential degenerative effects of either HBV or HCV $[11,12]$. Continuing hepatocyte death triggers compensatory repair and regeneration and eventually leads to severe fibrosis, the major clinical risk factor for the development of HCC $[4,5,13]$.

The HBV is a DNA virus that can integrate into the host genome and is considered a major risk factor for initiation and development of HCC [14]. The HBx gene of HBV encodes a viral protein that plays a central role in HBV infection and liver cancer [15-17]. Point mutations in the $H B x$ gene leading to exchanges at position 31 with serine to alanine (Ser31Ala), position 130 with lysine to methionine (Lys130Met), and position 131 with valine to isoleucine (Val131Ile) were found to be prevalent in patients with HCC $[18,19]$. The HBx protein is thought to play a major role in HCC by modifying apoptosis, inhibiting nucleotide excision and repair of damaged cellular DNA, and modulating transcriptional activation of cellular growth regulating genes [20]. Strong epidemiological evidence correlating HCC to HBV infection is demonstrated by the presence of $\mathrm{HB}$ surface antigen ( $\mathrm{HBs} \mathrm{Ag}$ ) and $\mathrm{HB}$ core antibodies (HBc antibodies) in the blood of HCC patients [21]. Hepatocyte transformation may also be indirectly influenced by HBV DNA integration [22]. Integrated HBV DNA is frequently observed in HCC, thereby suggesting that HBV has a direct oncogenic effect through interaction with transformation-associated genes [14]. Similarly HCV is an enveloped single-stranded positive-sense RNA virus, approximately $9.6 \mathrm{~kb}$ in length, and encodes a polyprotein of about 3000 amino acids [23] which is processed by viral-encoded and host-encoded enzymes into structural and non-structural proteins. This RNA virus does not integrate into the host genome but likely induces HCC through viral proteins by host-protein interactions or via the proinflammatory response to the virus [14]. Several HCV proteins, including core, NS3, and NS5A, have been shown to induce oxidative stress in cultured cells $[24,25]$. ROS, which act as second messengers, activate cellular kinases, although the mechanism of this activation remains unclear.

Alongside with etiological risk factors, environmental risk factors have also been reported to contribute to the development of HCC (Fig. 1). Alcoholic liver disease (steatohepatitis) has been shown to be an important risk factor for HCC development [26]. Alcohol either directly initiates HCC after its oxidation to acetaldehyde, which is genotoxic, or indirectly through causing cirrhosis [26,27]. Cigarette smoking is considered as one of the primary sources of exposure to 4-aminobiphenyl in humans. An important report measuring DNA adducts of 4-aminobiphenyl, a hepatic carcinogen showed a significant increase in HCC risk with increasing levels of adducts [27]. Diabetes increases the risk of HCC, as shown by the first population-based study to assess the risk of HCC in diabetic patients [28]. An increased risk of cancer mortality in general has long been associated with obesity [29].

It has been proposed that lipid accumulation in obesity induces a low-grade inflammatory response, which in turn increases IL-6 and TNF expression in adipose tissue and Kupffer cells. IL-6 and TNF are the main mediators in the development of steatohepatitis through activation of the JAK/STAT pathway leading to HCC development [30]. Non-alcoholic fatty liver disease (NAFLD), known as non-alcoholic steatohepatitis, is a risk factor for progressive liver disease [29]. Hepatic iron overload, or hemochromatosis can also lead to cirrhosis and ultimately to HCC. HCC is an important cause of mortality in cirrhotic patients with chronic hemochromatosis [31]. Increased cancer risk in a cohort of 230 patients with hereditary hemochromatosis in comparison to matched control patients with non-iron-related chronic liver disease [31]. It is an autosomal recessive condition with a homozygous $\mathrm{C} 282 \mathrm{Y}$ mutation in the HFE gene characterized by excessive iron deposition in hepatocytes due to increased intestinal absorption of iron from normal diet [32]. Thus, while liver disease is the commonest cause of death in patients with hereditary hemochromatosis, $6 \%$ of men and $1.5 \%$ of women are at absolute risk of liver cancer [31,32]. Aflatoxin is a mycotoxin that commonly contaminates corn, soybeans and peanuts, and is reported to be a cause for hepatocarcinogenesis [33]. High dietary aflatoxin intake has been associated with HCC. In another study from Shanghai, the odds of developing HCC in individuals with HBV and exposure to aflatoxin were 59.4 times that of the normal population [34]. Sex hormones, such as estrogens, progesterone, and oral contraceptives have been shown to increase hepatic tumor development in animals. Moreover, there have been several reports of HCC developing in patients who have been treated with androgenic or anabolic steroids or oral contraceptives [35,36].

\section{Role of STAT signaling pathway in the development of HCC}

Signal transducer and activator of transcription (STAT) protein was first discovered in 1993 by James Darnell [37]. It can be induced 


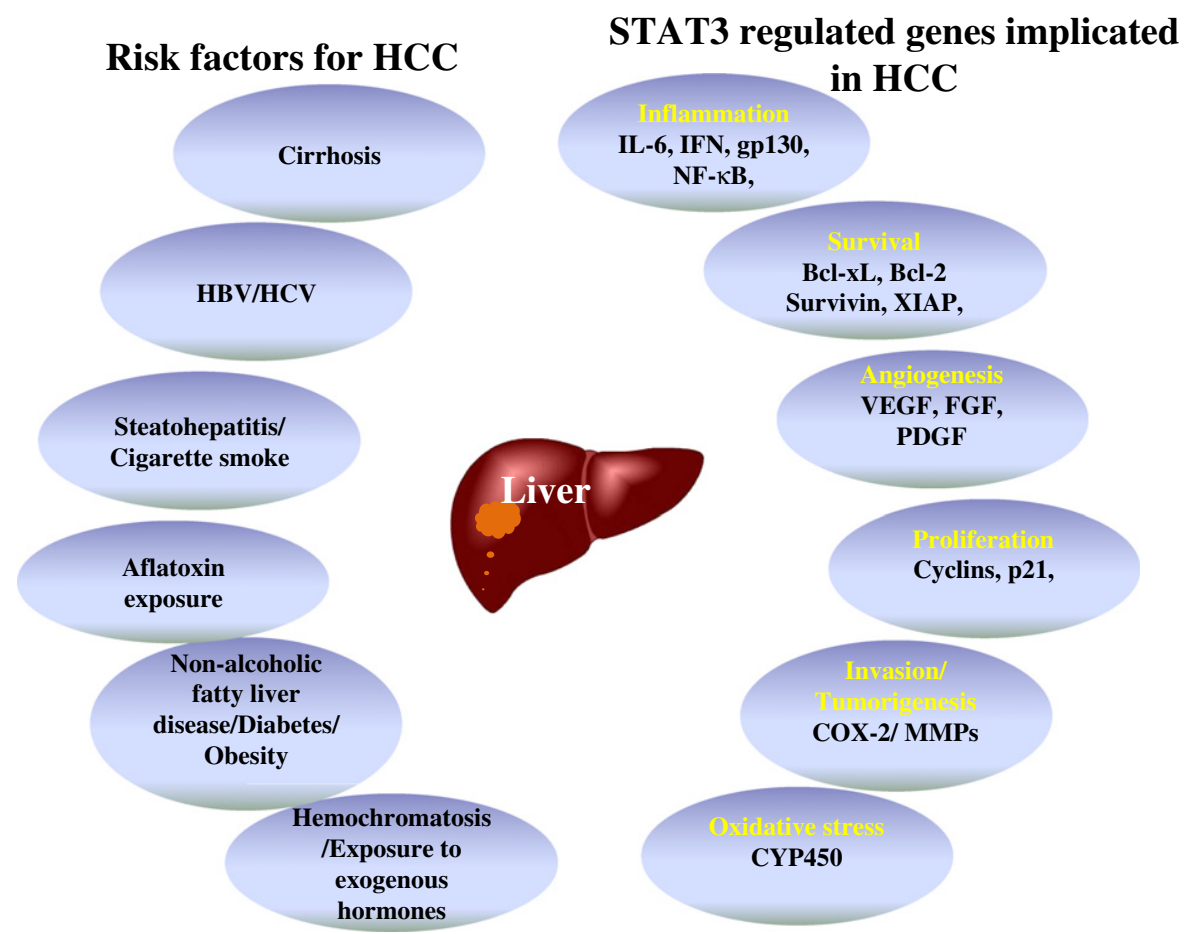

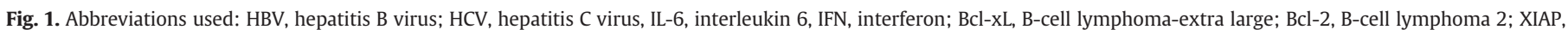

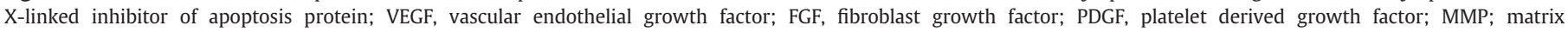
metalloproteinases; gp130, glycoprotein 130; COX-2, cyclooxygenase 2; CYP, cytochrome.

by signals from the cell membrane directly to the nucleus to activate gene transcription, thus evading the involvement of secondary messengers [37]. STAT proteins have been shown to play pivotal roles in cytokine signaling pathways, which are involved in regulating cell growth and differentiation in systems ranging from Dictyostelium to mammals [38]. STAT proteins have also been identified in Drosophila, [39,40] Caenorhabditis elegans and [41] Anopheles [42] but are strikingly absent in yeast [43]. The STAT family comprises seven members: STAT1, STAT2, STAT3, STAT4, STAT5a, STAT5b, and STAT6. They range in size from 750 to 850 amino acids [44], (Fig. 2). The entire STAT family can be divided into two groups, according to their specific functions. The first group is comprised of STAT2, STAT4, and STAT6, which are activated through a small number of cytokines and are engaged in the development of T-cells and IFN- $\gamma$ signaling. The other group consists of STAT1, STAT3, and STAT5, which are activated in different tissues through a series of ligands and are involved in IFN signaling, development of mammary glands and response to $\mathrm{GH}$, and embryogenesis, respectively. This latter group of STATs plays a key role in controlling cell-cycle progression and apoptosis and thus contributes to oncogenesis [45]. All the STAT members are organized on 3 different chromosomes. In the human genome, STAT1 and STAT4 are clustered on chromosome 2, whereas STAT3, STAT5a, and STAT5b are huddled together on chromosome 17, and STAT2 and STAT6 are assembled on chromosome $12[44,46]$.

\section{Structure of STAT3 isoforms}

\section{STAT3 $\alpha(92 \mathrm{kDa}, \mathrm{p}-\mathrm{Tyr}$ at position 705; p-Ser at position 727)}

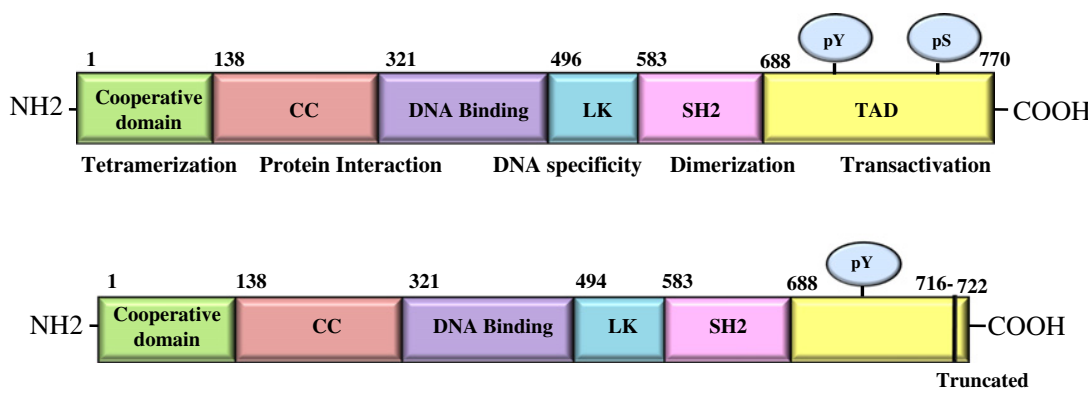

STAT3 $\beta$ (89kDa, pTyr at position 705; No Serine phosphorylation )

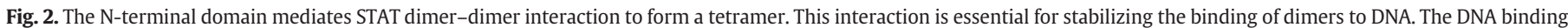

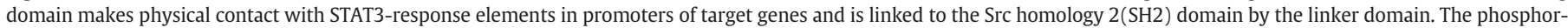

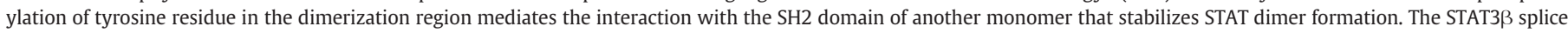

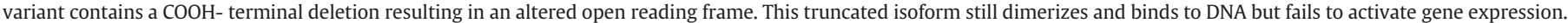


Among other STAT family proteins, STAT3 has received considerable attention during the last decade since it is a convergent point for a number of oncogenic signaling pathways and controls intra-cellular signal transduction pathways of several pro-inflammatory cytokines and growth factors that are implicated in liver damage and repair mechanisms [47-50]. STAT3 was initially identified as an acute phase response factor (APRF), an inducible DNA binding protein that binds to the IL-6 responsive element within the promoters of hepatic acute phase genes [51] and as a DNA binding protein in response to epidermal growth factor [52]. The gene that encodes STAT3 is located on chromosome 17q21. The $92 \mathrm{kDa}$ protein is 770 amino acids long [53]. A splice variant of the mammalian STAT3 with deletion of a 50 nucleotides sequence near the C-terminus, codes for an 80-kDa STAT3 isomer (STAT3b) that functions as a negative regulator of STAT3 [20].

STAT3 can be activated by IL-6, leukemia inhibitory factor (LIF), oncostatin M, and the ciliary neurotrophic factor (CNTF) family of cytokines, which are all known to mediate their signal through the gp130 protein [54-56]. These receptor molecules harbor a common STAT3 docking motif (YxxQ) in their cytoplasmic domain [57]. Indeed, the expression of IL-6, one of the major STAT3 activating cytokines, is elevated in human liver diseases and HCC [58,59]. IL-6 is a key event in tumorigenesis with high levels associated with HCC [60]. One of the normal functions of IL-6 in adult liver is to protect against apoptosis via STAT3 pathway following viral infection or ingestion of chemicals $[61,62]$. When IL-6 binds to its specific receptor subunit, it can induce dimerization of the gp130 receptor and activation of the gp130-associated Janus kinase (JAK). As in the gp130-deleted animals, no STAT3 DNA binding was found, and activation is likely to be mediated through a gp130-dependent cytokine while in IL-6 null animals, no STAT3 activation was found [63]. IL-6 levels in liver cancer patients are 25-fold higher than in healthy adults [64]. Subsequent studies showed that the levels of IL-6 in SNU-387 and SNU-449 liver cancer cell lines were much higher than those in human hepatocytes [65]. Acute-phase response is impaired in both IL-6 and STAT3-deficient animals. It is most likely that the $\mathrm{L}-/-$ STAT3 mice failed to survive because there was a disturbance in the acute-phase response, which is fundamentally dependent on STAT3 activation [66]. Another cytokine, IL-22 induced phosphorylation of STAT3 on a serine residue and has been shown to induce acute phase genes in the liver [67], an effect that has been described to be regulated by IL-6 mainly through STAT3 activation. It has been shown that STAT3 Ser727 phosphorylation is induced upon IL-22 stimulation and is required for maximal transcriptional activation [68].

Recent findings indicate that STAT activation is not mediated exclusively by cytokine receptors that lack intrinsic tyrosine kinase domains. STAT proteins are also triggered by receptor tyrosine kinases such as epidermal growth factor-receptor (EGF-R), PDGF-R [69], and colony stimulating factor-1R (CSF-1R) [70], seven transmembrane G-protein-coupled receptors such as angiotensin II receptor [71] and serotonin 5-HT2A receptor [72] and through the T cell receptor complex [73] and the CD40 receptor [74]. EGF, TGFB, and PDGF receptors are also capable of directly phosphorylating STAT proteins in the absence of JAK activation, leading to the up-regulation of genes that promote cell proliferation, survival, and cell transformation [75-77].

The malignant transformation of hepatocytes in humans is a multi-step process that occurs through progressive sequential evolution of chronic liver injury, regeneration, fibrosis and cirrhosis, small cell dysplasia, and low-grade and high-grade dysplastic nodules, resulting in the formation of fully developed HCC $[78,79]$. Different subtypes of preneoplastic and neoplastic liver lesions may exhibit common alterations of some key signal transduction pathways that underlie cell survival and proliferation. Interference with these molecular mechanisms may be essential for HCC prevention and treatment. These may involve over expression of several cytokines (interleukins 1-11) and their receptors, growth factors and their receptors, including vascular endothelial growth factor (VEGF), and platelet-derived growth factor (PDGF) [69]. Transforming growth factor (TGF) and epidermal growth factor (EGF) receptors (also known as ErbB1), fibroblast growth factor (FGF)), and its FGF receptor, hepatocyte growth factor (HGF) receptor (with unchanged or diminished expression of HGF), and insulin-like growth factor (IGF) family members are also thought to play an important role in hepatocarcinogenesis. These ligands and their receptors activate various signal transduction pathways, including the JAK/STAT3 pathway, a critical signaling pathway that supports the proliferation of preneoplastic and neoplastic liver lesions [80].

\section{Structure of STAT proteins}

STAT proteins exhibit a modular structure with highly defined domains, which include the $\mathrm{N}$-terminal coiled-coil domain, DNA binding domain, a linker, SH2 domain, and a C-terminal transactivation domain [77]. Each of these domains is important for the physiological functions of STAT proteins [81]. The analysis of the crystal structure of an NH2 conserved-terminal domain with $\sim 130$ residues show that it is formed of eight $\alpha$-helices that can form a hook like interface which is involved in protein-protein polar interactions affecting transcription, and thereby enhance the ability of dimerized STATs to bind to DNA [82]. The N-terminal domain is involved in STAT dimerization and also in tertramerization interactions. The tetramerization of STATs contributes to stability of the STAT-DNA binding by means of the interaction with randomly arranged low-affinity STAT binding sites, thus increasing transcriptional activity [83]. Several studies have implicated the $\mathrm{N}$-domain in various protein-protein interactions affecting transcription and it has been suggested that this domain enables dimerized STAT molecules to polymerize and to bind multiple DNA sites that are involved in oncogenic growth signaling pathways [84]. The region of STATs between residues 130 and 315 consists of a four-stranded helical coiled coil domain. This domain associates with a number of potentially important regulatory modifiers, including IRF-9 and STIP1 which are ligand dependent [85]. A sub-region of the C-terminal domain and the coiled-coil domain are necessary for receptor binding and functional recruitment of STAT3 to gp130 upon stimulation with IL-6 [86], (Fig. 2).

The DNA-binding domain forms complexes between STAT proteins and DNA and determines the DNA-binding specificity for each STAT protein [87]. In this domain, a region of beta-sheet structures is connected by unstructured loops. The DNA-binding domain adopts an immunoglobulin-fold structure, and binds to DNA as a dimer. It is also involved in nuclear translocation, probably by maintaining proper conformation for importin binding and to exportin when STAT is dephosphorylated and exiting the nucleus [88]. A linker domain from $\sim 500-575$ is $\alpha$-helical followed by a classical $-\mathrm{SH} 2$ domain [89]. Domain SH2, sited in the region between the amino acid residues 600 and 700, is essential for the recruitment of STATs to phosphorylated receptors and for the dimerization between two activated STAT monomers through reciprocal phospho-tyrosine (pTyr)-SH2-domain interactions between monomeric STATs to form dimers [89]. The differences in the STAT SH2 domain bring about selectivity of the STAT protein-binding to the different cytokine receptors [20], which in turn appear to be critical for nuclear localization and DNA-binding activities. Thus, it is critical for the recruitment of STATs to the activated receptor complexes and is also required for the interaction with JAK and Src kinases. It is also possible that this domain participates in other protein-protein interactions that have not yet been fully deciphered [89]. The Src homology 2 (SH2) domain-containing protein tyrosine phosphatase, SHP-2, interacts with many proteins by recognizing the tyrosine-phosphorylated $\mathrm{Y}$ (I/V)X(L/V/I) motifs through its amino-terminal SH2 domain [90].

The C-terminal portion of the protein, which functions as the transcriptional activation domain (TAD), is natively unfolded and forms 
structure only upon binding with interacting partners and is involved in communication with transcriptional complexes [89]. Immediately downstream of the $\mathrm{SH} 2$ domain, in position 705, is a tyrosine residue, which plays a critical role in STAT activation [20]. Three-dimensional structure of the Stat $3 \beta$ homodimer bound to DNA. Phosphorylation of this tyrosine appears to be achieved by growth factor receptors as well as JAK and Src kinases, depending on the nature of the cell type and the ligand/receptor interactions [89]. This has been found to be essential for the activation and dimerization of STATs. A conserved serine in this STAT domain (apart from STAT2 and STAT6, which have no such serine, is a phosphorylation site and regulates STAT transcriptional activity [89]. STAT1 and 3, which have an altered serine, have their transcriptional capacity reduced by $20 \%$ [91]. Structural determination of the transactivation domain is essential to understand its binding partners, which may provide crucial insight into the regulation of this domain, and how it interacts with other proteins in the transcriptional process.

\section{Structure of JAK family proteins}

JAKs phosphorylate STAT proteins when activated by signals from interleukins and other cytokines. The unique structure of the JAKs clearly separates them from other members of the protein tyrosine kinase family [92], (Fig. 3). The most critical feature of these proteins is the presence of two JAK homology $(\mathrm{JH})$ domains, $\mathrm{JH} 1$ and $\mathrm{JH} 2$, which share extensive homology to tyrosine kinase domains. JH1 domain is a functional tyrosine kinase domain but the JH2 domain, lacks observable tyrosine kinase activity $[93,94]$. The SH2 domain also contains JH3 and JH4 domains [95]. However, despite of the homology to SH2 sequences, these regions do not directly bind to phosphotyrosine residues [96-98]. The JH6-JH7 domains comprise the FERM domain, and the residues located in the JH7 domain mediate binding to the box 1 /proline-rich region of cytokine receptors $[93,99,100]$. Moreover, this interaction between JAKs and cytokine receptors can regulate receptor localization [101,102]. Specifically, the surface expression of EPO receptors is regulated by the FERM domain of JAK2 [103] and both JAK2 and TYK2 have been shown to inhibit the proteasomal degradation of the thrombopoietin receptor [99]. The selectivity of STAT activation by various ligands is determined mainly by the highly specific interactions between the $\mathrm{SH} 2$ domain and the phosphotyrosine residues on each receptor [94]. Although JAK kinases have not been shown to have any substrate specificities, they do have different specific biological functions, as demonstrated in vivo by gene targeting studies [104-106].

\section{Src family of kinases (SFK)}

Src comprises a family of 9 tyrosine kinases that regulate cellular responses to extra-cellular stimuli [107]. SFKs have a critical role in cell adhesion, invasion, proliferation, survival, and angiogenesis during tumor development [35]. They share similar structure and function. Over expression or high activation of SFKs occurs frequently in tumor tissues and they are central mediators in multiple signaling pathways that are important in oncogenesis [108]. SFKs can interact with tyrosine kinase receptors, such as EGFR and the VEGF receptor. The Src family of cytoplasmic non-receptor protein tyrosine kinases was first discovered in the context of the transforming retroviral oncogene $\mathrm{v}$-src, which is responsible for the potent sarcoma-inducing activity of the Rous sarcoma virus [109]. Src kinase is representative of the non-receptor tyrosine kinases which are present in essentially all metazoan cells, where their regulated activation by diverse growth factor, cytokine, adhesion, and antigen receptors is critical for generating an appropriate cellular response to external stimuli [35,107]. The nine members of the Src family include Src, Lck, Hck, Fyn, Blk, Lyn, Fgr, Yes and Yrk. SFK proteins range in molecular mass from 52 to $62 \mathrm{kDa}$ and share a conserved domain structure consisting of consecutive SH4 domain, unique domain, SH3 domain, SH2-SH3 linker, SH2 domain, SH1 (catalytic domain), and C-terminal negative regulatory region. The SH3 domain contributes to substrate recruitment [110,111] and is critical for the regulation of kinase activity [112-114], (Fig. 4). The SH3 domain can bind to proline rich peptide binding sites and thus is important for protein-protein interactions. The SH2 domain also functions in protein-protein interaction(s) by virtue of its affinity for phosphotyrosine-containing peptide sequences [115,116]. All family members also contain an SH4 membrane-targeting region at their N-terminus, is always myristoylated and sometimes palmitoylated prior to membrane localization [117,118]. The SH4 region is followed by an 'unique' domain, which is the only non-conserved region within the kinase family [119]. It contains 50-70 residues which are divergent among family members and also contain a C-terminal regulatory region [119]. The unique domain is followed by modular SH3 and SH2 domains, a regulatory linker, the catalytic or kinase domain (SH1 domain), and a C-terminal negative regulatory tail.

\section{Activation of STAT3}

STAT activation by phosphorylation is highly regulated and transient. Unphosphorylated STAT exists predominantly as dimers, with a small fraction as monomers and higher-order complexes, which shuttle continuously between the cytoplasm and nucleus in the latent state [120]. In this "resting" state, there is also a small fraction of STATs that is hypo-phosphorylated, with low level of serine, and threonine phosphorylation. In this latent state, the STAT dimer was postulated to be in the anti-parallel conformation in the cytoplasm as inactive homodimers [121]. STAT signaling is critical for normal cellular processes such as embryonic development, organogenesis and organ function, innate and adaptive immune function, regulation of cell differentiation, growth, and apoptosis [122-127]. In normal cells, STAT3 protein activation is strictly controlled to prevent unscheduled gene regulation, while constitutive activation of STAT3 has been detected in a wide number of human cancer cell lines and primary tumors, such as $50 \%$ of HCC, leukemias, lymphomas, multiple myelomas, prostate, gastric, breast, lung, and head and neck cancer [128-134].

Peak STAT3 phosphorylation occurs within 15-60 min of exposure to cytokine, and even in the presence of continuous cytokine,

\section{Structure of Janus Kinase}

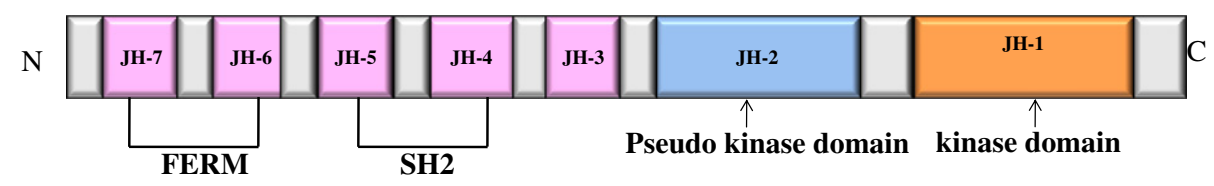

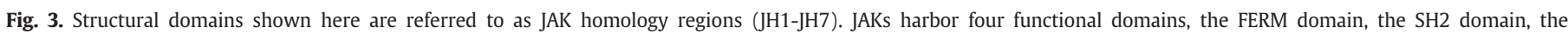
pseudotyrosine kinase (TK) domain and a catalytically active TK domain. 


\section{Structure of Src Kinase}

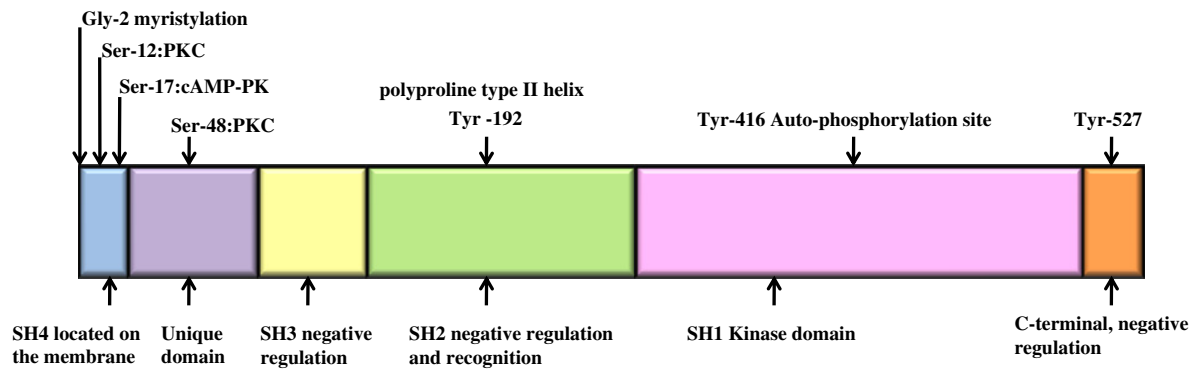

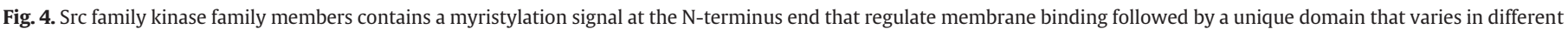
family members. A conserved auto-phosphorylation site (Tyr-416) and negative regulatory tyrosine (Tyr-527) is also unique feature of Src kinases.

STAT3 activation decreases over several hours [135]. This constitutive activation of STAT3 is not due to mutations in STAT3 but occurs due to deregulation of protein tyrosine kinases or constitutive release of growth factors that activate STAT3 [136]. Binding of cytokines or growth factors to their surface receptors resulted in rearrangement of antiparallel unphosphorylated STAT dimers in the cytoplasm as parallel unphosphorylated dimers [120]. The phosphorylation is mediated through the activation of non-receptor protein tyrosine kinases called Janus-like kinase (JAK). JAK1, JAK2, JAK3, and tyrosine protein kinase 2 have been implicated in the activation of STAT3 [137]. In addition, the role of c-Src kinase has been shown in STAT3 phosphorylation [138].

When IL- 6 binds to its specific receptor subunit, it can induce dimerization of gp130 receptor and activation of the gp130-associated JAK $[52,139]$. The critical role of JAKs in cytokine signaling is evident by the inherited immune-deficiencies caused by mutations that prevent receptor-JAK interactions or the kinase activity of the JAKs [38]. JAKs can either bind to intracellular domains of cytokine receptor signaling chains or catalyze ligand-induced phosphorylation of intracellular tyrosine residues on the receptor [140]. The JAKs in turn phosphorylate the specific tyrosines in the intracellular domain of gp130, providing docking sites for the Src homology 2 (SH2) domain of signaling molecules of STAT3. Phosphorylation of STAT3 has been shown to occur both at the tyrosine 705 (Y705) and at the serine 727 (S727) residue on their cytoplasmic tail [141]. Homo- or heterodimerization of STATs are achieved via reciprocal binding of this critical pTyr of one monomer and $\mathrm{SH} 2$ domain of the partner dimer [52]. Activated STAT dimers can translocate into the nucleus and bind to specific elements [52]. STAT homodimers bind to members of the IFN- $\gamma$ activated sequences (GAS) family of enhancers (TTCNNNGAA). Most STAT dimers recognize an 8- to 10-base pair inverted repeat DNA element with a consensus sequence of 5-TT(N) AA-3. The observed variation in the binding affinity of a particular activated STAT dimer for a single target DNA sequence is determined by differences in the nucleotide sequence [140]. Other known STAT modifications include arginine methylation, ubiquitination and sumoylation covalent modifications [142].

Unlike other STATs, such as STAT1 and STAT2, which accumulate in the nucleus only after phosphorylation, STAT3 can enter the nucleus independent of its phosphorylation. Activated STATs shuttle more rapidly than non-activated ones $[143,144]$. Direct interaction of unphosphorylated STATs with the nuclear pore proteins (nucleoporins) Nup153 and Nup214 allows carrier-independent nuclear translocation. Nuclear translocation of activated STATs is mediated by the karyopherin family of transport proteins called importins or exportins depending on their movement direction [121]. Cytokine-induced nuclear import involves binding to importin and following inactivation, the nuclear export of STATs involves a CRM1 (chromosome region maintenance 1)/ exportin1-dependent process [88]. Specific sequence motifs on the surface of STATs, known as nuclear localization signals and nuclear export signals, allow STAT-importin and STAT-exportin interactions [88]. Additionally, specific adaptor molecules, the importin family, are involved in STAT-importin interaction. Distinct importin subtypes determine trafficking of different STATs. STAT activation with nuclear accumulation terminates within minutes [145,146]. Recently, nucleocytoplasmic shuttling of STAT3 was shown by fluorescence localization, after photobleaching (FLAP), to be a dynamic process that involves constitutive shuttling of unstimulated STAT3 in the absence of cytokine stimulation [144]. Both import and export signals contribute to the balanced shuttling and IL- 6 induction reduces the nuclear export signal, resulting in nuclear accumulation of STAT3. Nuclear STAT3 can then bind to specific promoter elements on DNA and activate target gene transcription [139]. Extensive research in the past decades have shown that STATs can control cell growth and differentiation and unraveled many structural features, regulatory mechanisms and functions, and are involved in the regulation of the cells of the immune system and in development of organs and tissues. Most importantly STATs are activated in pathological states such as inflammation and cancer.

\section{Functions of STAT3}

The functions of STAT3 have been more difficult to define from knockout mice studies as the embryos die early in embryogenesis [147]. In fact, loss of STAT3 is lethal even to embryonic stem cells [148] indicating a key role for STAT3 in cell growth and/or survival. Also, by 7.5 days post-coitum, STAT3 mRNA is substantially expressed in the extra embryonic visceral endoderm, which is the principal site of nutrient exchange between the maternal and embryonic environments $[148,149]$. STAT3 signaling also seems to play important roles in several liver functions. Conditional knock-out of STAT3 expression partially impairs liver regeneration [150] whereas tissue-specific knock-out of hepatic STAT3 was found to affect glucose homeostasis and induction of insulin resistance [151]. In addition to being associated with cell growth, STAT3 activation has been found to be critical for differentiation of keratinocytes [152], and myeloid cells [153], and plays an important role in mediating the formation of epithelial tubules in response to hepatocyte growth factor [154]. Selective loss of STAT3 in keratinocytes results in impaired wound healing, and skin-specific STAT3-transgenic mice develop psoriasis [155]. In-vitro studies on keratinocytes have shown that STAT3 plays an important role in the migration of epidermal cells, and is essential for skin renovation [156].

STAT3 is also involved in the involution of the post-lactating mammary gland [157]. This is an apoptotic process involving the epithelial cells and results from an increased level of the insulin-like growth factor binding protein-5 (IGFBP5) $[87,91,158]$. Selective targeting of the STAT3b isoform was reported and mice exhibit diminished recovery 
from endotoxic shock and hyper-responsiveness of some endotoxininducible genes in liver. This is the first in vivo evidence that STAT isoforms have essential in vivo functions [159]. Whether other STATs have similar cytoplasmic function is yet to be determined. In addition, the functions of STATs in other cytosolic compartments are obscure. The non-canonical regulation and function of non-phosphorylated STATs is certainly an exciting new area of research interest.

\section{Negative regulators of STAT3}

In normal cells, the extent and duration of STAT activation is controlled by a variety of mechanisms. These include feedback inhibition of the JAK/STAT pathway by suppressor of cytokine signaling proteins (SOCS) 1 and 3 or cytokine-inducible SH2-containing (CIS) protein through inhibition and/or degradation of JAKs, dephosphorylation of the receptor complex or nuclear STAT dimers by protein tyrosine phosphatases (PTPases) and interaction of activated STATs with inhibitory molecules from the protein inhibitors of activated STAT (PIAS) family [160-162]. Other physiological negative protein modulators of the STAT3 signaling pathway also involving negative regulation include the JAK binding protein (JAB) and STAT-induced STAT inhibitor [163].

Cytokine-inducible SH2-containing (CIS) protein, the first member of the SOCS family, was originally identified in 1995 as a cytokine-inducible early gene [164]. The most intensively studied group of negative regulators is the SOCS proteins [165]. Because of their Src homology 2 domains, this family of eight cytokine-inducible proteins (SOCS1-SOCS7 and CIS) binds phosphorylated receptors and/ or JAKs and thereby interferes with signaling. The second member of the SOCS family, SOCS-1 (or JAK-binding protein, JAB; STAT-induced STAT inhibitor-1, SSI-1) was independently identified in 1997 by three different groups [166-168]. JAB was identified using a yeast two-hybrid system as a protein that bound the catalytic domain of JAK2 [167]. SSI-1 was identified as a STAT-inducible inhibitor using a monoclonal antibody to the sequence motif of the STAT3 SH2 domain [168]. SOCS-1, -2 , and -3 were cloned as inhibitors of IL-6 signaling using the murine monocytic leukemic M1 cell line [166].

SOCS, also known as STAT-induced STAT inhibitor (SSI) protein family comprises several members including SOCS1, SOCS2 and SOCS3 which are encoded by genes located in 16p13.13, 12q, $17 q 25.3$, respectively $[164,169]$. SOCS proteins have a variable NH2-terminal domain, a central SH2 domain, and a $\mathrm{COOH}$-terminal domain, termed SOCS-box motif [170-172]. The SOCS box is a sequence of 40 amino acids that is conserved throughout the SOCS family. The SOCS box is thought to influence the stability of SOCS proteins [173-175]. The SOCS box appears to mediate interactions with Elongins B and C, which may target proteins for proteasomal degradation [175]. SOCS proteins are induced by cytokines and act in a negative feedback loop to inhibit the receptor. The SH2 domain of SOCS proteins is able to interact with a specific phosphorylated tyrosine residue in the kinase inhibitory region of JAK molecules with high affinity, resulting in the inhibition of STAT phosphorylation. Another domain in SOCS proteins interacts with elongins B and C, and couples the $\mathrm{SH} 2$ domain-binding proteins to the ubiquitin-proteasome pathway [175-177]. COOH-terminal domain SOCS box is responsible for the recruitment of the ubiquitin transferase complex. SOCS1 inhibits JAK activation through its N-terminal kinase inhibitory region (KIR) by direct binding to the activation loop of JAKs, while SOCS3 inhibits JAK kinase by binding to the cytokine receptor through its SH2 domain [174,176].

Among the eight members of the SOCS family, SOCS-1 and SOCS-3 appear to be relevant to several aspects of hepatic pathobiology. For example, SOCS-3 is up-regulated 40 -fold $2 \mathrm{~h}$ after partial hepatectomy in mice [178]. It has been reported that SOCS-1 and SOCS-3, negative regulators of the JAK2-STAT signaling pathway, are silenced by methylation in human hepatoma cell lines and HCC tissues, which leads to constitutive activation of STAT3 in these cells $[179,180]$. Downregulation of the SOCS-1 may be a crucial event in the hepato-carcinogenic process leading to formation of HCC. Additionally, the results of several studies have shown that forced expression of SOCS1 prevents liver injury [181] and inhibits the abnormal growth of HCC cells [179,182].

The protein inhibitors of activated STATs (PIAS) family of proteins are a negative regulator of STAT-mediated gene transcription $[183,184]$. The four family members, including alternatively spliced isoforms, have various names that reflect how they were identified: PIAS1 (Gu-binding protein (GBP), PIAS3, PIAS3ß (potassium channelassociated protein (KchaP), PIASxa (androgen receptor-interacting protein 3 (ARIP3), PIASXß (MsX-interacting zinc finger protein 1 (Miz1) and PIASy. A Drosophila PIAS homolog, dPIAS (or Zimp), that negatively regulates the JAK-STAT pathway also exists [183]. PIAS proteins contain a SAP (SAF-A/B, Acinus and PIAS) domain, a ring-finger domain and C-terminal serine/threonine rich domain. Although PIAS proteins inhibit STAT mediated gene activation, they inhibit distinct STAT proteins by different modes. For example, PIAS3 inhibits STAT3 and STAT5, whereas PIAS1 blocks STAT1-dependent signaling [185] and directly inhibits STAT-DNA binding activity and recruits other transcriptional co-repressors such as histone deacetylases (HDACs). Furthermore, they have small ubiquitin related modifier (SUMO) E3 ligase activity [183]. Upon cytokine stimulation, PIAS-1 and PIAS-3 bind activated STAT1 and -3 , respectively, and prevent their ability to bind to DNA [184].

Phosphatases are reported to be involved in regulating JAKs and STATs. Numerous PTPs have been implicated in STAT3 signaling including SHP1, SH-PTP2, TC-PTP, PTEN, PTP-1D, CD45, PTP-e, LMW, and PTP [186]. Cytosolic and membrane-bound phosphatases inhibit JAKs, whereas nuclear phosphatases terminate STAT signaling. Three types of PTPs have been shown to negatively regulate JAK-STAT pathways. The first phosphatases that demonstrated a regulatory role in this pathway are the SH2-containing phosphatases. SHP1 is implicated in the negative regulation of JAK/STAT signaling pathways [187] and it has been found that loss of SHP1 may contribute to the activation of JAK or STAT proteins in cancer [188]. The second phosphatase that negatively regulates JAK-STAT signaling is the transmembrane PTPase CD45, which is highly expressed in all hematopoietic lineages at all stages of development and is a key regulator of antigen receptor signaling in $\mathrm{T}$ and B cells [90]. Although Src family kinases were identified as primary molecular targets for CD45, targeted disruption of the CD45 gene leads to enhanced cytokine and IFN receptor-mediated activation of JAKs and STAT proteins. Two PTPases, SHP-1 and SHP-2, as well as a protein serine/threonine phosphatase, PP2A, are also strongly implicated in STAT signaling, including STAT1, STAT3 and STAT5 [188]. This suggests that loss of SHP1 is linked to constitutive high levels of activated STAT3. However, it is not clear whether or not the upregulation of SOCS-1, CIS, and PIAS3 can act as a compensatory mechanism to constitutively active STAT3.

\section{Role of STAT3 in oncogenic transformation}

Constitutive activation of STAT3 is involved in many cellular processes including cell growth, survival, metastasis, angiogenesis, and immune suppression, all of which favor HCC initiation and progression [189]. A critical role for STAT3 in malignant transformation was first proposed after initial studies showed that STAT3 is constitutively activated during v-Src transformation. STAT3 signaling is required for oncogenic transformation by $v$-Src $[108,190-192]$. Blocking of STAT3 DNA binding with antisense oligonucleotides or a dominant-negative STAT3 protein, further established the critical role of STAT3 in oncogenesis [128,193,194]. In all cases, inhibition of persistent STAT3 signaling suppressed the transformed phenotype and tumor progression. Constitutive activation of STAT3 has been frequently detected in clinical incidences of HCC and in more than 50\% of human HCC cell lines but not 
in normal or non-transformed liver cells [179,180,195]. For example, STAT3 was found to be over expressed in proteome microarray analysis of primary HCC [196]. Its phosphorylation was highly positive in immunohistochemical analysis of HCC biopsies [197] while increased STAT3 DNA binding activity was observed in chemically-induced HCC [198]. This is surprising, since rapid activation of the STAT3 transcriptional complex has been reported in the regenerating liver following partial hepatectomy [199]. Also, STAT3 antisense oligonucleotide has been reported to significantly reduce the amount of STAT3 protein and inhibit cell proliferation and tumorigenic growth of several human HCC cell lines transplanted into mice [195]. Activating mutations in the gene encoding the gp130 signaling subunit of IL-6 receptor family members have been identified in benign hepatic adenomas [200]. Elevated STAT3 and p705 STAT3 expression in HCC tissue has also been reported [120]. Recent data also indicate an association of pSTAT3 with the histological grade of HCC tissue from 67 patients [201]. When anti-cancer small molecule S3I-201 was administered at a dose of $5 \mathrm{mg} / \mathrm{kg}$ every other day to xenografts of the human HCC cell line HUH-7, it was found that S3I-201 inhibited STAT3 tyrosine phosphorylation and tumor growth [6]. The amelioration of the malignant behaviors of HCCLM3 following orthotopic implantation, included impeded migration, hampered neovascularization, inhibited local metastasis, and reduced lung metastasis, indicating that STAT3 also mediates the metastatic potential of HCCLM3, a highly malignant variant of HCC [195].

STAT3 can also act as a stem cell renewal factor, and hyperactive STAT3 signaling results in enhanced liver progenitor cell proliferation [202]. In addition, over-expression of a constitutively active form of STAT3 in immortalized rat or mouse fibroblasts induced tumors in nude mice [203]. Owing to its role in modulating stem cell survival, proliferation and transformation, STAT3 is thought to be critical for cancer stem cell survival in some tissues [204]. Studies from STAT3-deficient mice (STAT3 $\Delta$ hep) were found to exhibit more than a 6-fold reduction in HCC load relative to STAT3F/F mice [46]. Furthermore, tumors in STAT3 mice were smaller, suggesting that STAT3 may play a role in HCC cell proliferation and/or survival. Deletion of STAT3 in cultured STAT3F/F dih cells, accomplished by infecting the cells with a Cre-expressing adenovirus, resulted in cell death, suggesting that activated STAT3 is required for the survival of HCC cells. Although cells that are completely STAT3-deficient cannot survive, cells with a partial reduction of STAT3 expression, accomplished by shRNA transduction are viable, but exhibit a senescent phenotype and fail to form subcutaneous tumors upon transplantation [205].

One can conclude from the above reports that STAT3 indeed plays a major role in HCC initiation and development. As compelling data continue to accumulate, STAT3 has become an attractive molecular target both for the prevention and treatment of HCC and various pharmacological inhibitors derived from synthetic and natural sources have been employed to target aberrant STAT3 activation in HCC (Table 1). While safety remains a point of concern, given the fact that STAT3-null mice are embryonically lethal, tissue-specific STAT3 deletion experiments have indicated that STAT3 may not be essential for the survival of normal differentiated cells. These results provide further evidence that it may be safe to target STAT3 for HCC therapy [206].

\section{Role of STAT3 in inflammation}

Various published studies indicate the potential role of HCC as a pro-inflammatory transcription factor in HCC and other malignancies [207]. STAT3 was initially discovered as an acute-phase response protein, thus suggesting its casual link to inflammation [51]. IL-6 is one of the major mediators of inflammation and primarily exerts its effects through the activation of the STAT3 pathway [52]. Also, in various tumors, STAT3 can directly interact with nuclear factor NF- $\kappa$ B family member RELA, trapping it in the nucleus and thereby contributing to constitutive NF- $\kappa B$ activation in cancer [208]. STAT3 has also been shown to increase NF- $\mathrm{BB}$ activity in cancer cells while persistent activation of STAT3 in tumors, especially in immune cells of the tumor microenvironment, is dependent on NF- $\kappa \mathrm{B}$. This reciprocal relationship with RELA stems from the fact that several cytokines and growth factors encoded by RELA target genes such as IL-6 are STAT3 activators in HCC [206].

Another elegant study by Nadiminty et al. showed that active but not latent STAT3 induces p100 processing to p52 through the activation of IKK and that the subsequent phosphorylation of p100 indicates the diverse targets of STAT3 and may show the use of multiple pathways by cancer cells to survive and escape therapy [209]. The processing of p100 to p52 is a tightly controlled event in many cells and tissues. Constitutive processing of p100 protein resulting in the over expression of $\mathrm{p} 52$ leads to lymphocyte hyperplasia and transformation [179]. The p65 subunit of NF- $\kappa \mathrm{B}$ has been shown to interact with STAT3 $[205,210]$. Also, some of the target genes for NF- $\kappa$ B and STAT3 overlap and in addition, the two transcription factors are engaged in both positive and negative cross-talk [210]. In mouse DEN model, DEN-induced hepatocyte death results in release of IL- $1 \alpha$ which in turn can activate NF-kB signaling in Kupffer cells, and produce a panel of cytokines and growth factors, including IL-6 [211]. IL-6 released by Kupffer cells activates STAT3 in hepatocytes and STAT3-activated genes are critical for compensatory hepatocyte proliferation and liver tumorigenesis [60,205].

There are also few reports in literature that have analyzed the potential cross talk between STAT3 and Wnt/ $\beta$-catenin signaling pathways in HCC. Wang et al. by using Hepatitis B virus X (HBx) transgenic mice and a 3,5-diethoxycarbonyl-1,4-dihydrocollidine (DDC)-induced liver injury model, the relationship between HBx expression and tumorigenicity of hepatic progenitor cells (HPCs) was analyzed. All HBx transgenic mice developed liver tumors characterized by histological features of both HCC and cholangiocarcinoma after 7 months of DDC feeding. They also found higher titers of circulating IL-6, activities of IL-6/STAT3, and Wnt/3-catenin signaling pathways in HBx transgenic mice, suggesting HBx may induce intrinsic changes in HPCs by way of the above signaling cascades that may enable HPCs with tumorigenicity potential [212]. In another study, while evaluating the role of Wnt/ $\beta$-catenin signaling cascade in HCC development, Wang and coworkers found that transfection with $\beta$-catenin siRNA in HepG2 cells effectively knocked down $\beta$-catenin mRNA and protein expression levels and also suppressed tumor cell proliferation. Flow cytometry assay showed that tumor cells were arrested at the G0/G1 phase of the cell cycles. However, there no change was observed between the expression of STAT3 and the HSP27 protein following transfection [213]. Also, recent studies have indicated that a number of signaling cascades including STAT3 and Wnt/ $\beta$-catenin pathways may play an important role in the development of hepatic cancer stem cells [214]. For example, in order to understand the role of Oct4 in HCC and the relationship among Oct4 and Wnt/ $\beta$-catenin and TGF- $\beta$ signal pathways, Yuan and coworkers detected the expression of Oct4, Nanog, Sox2, STAT3 as well as the genes in Wnt/ $\beta$-catenin, and TGF- $\beta$ families in HCC cell lines and in tumor specimens from HCC patients. They observed that both HCC cell lines and HCC samples from patients express more than one key modulator in embryonic development such as Oct4, Nanog, Sox2, and STAT3 together with the genes in $\mathrm{Wnt} / \beta$-catenin and TGF- $\beta$ families. Knocking down Oct 4 reduced the expression of TGF- $\beta$ family genes Wnt/ $\beta$-catenin family genes, as well as STAT3 [215]. Overall, the exact crosstalk between STAT3 and Wnt/B-catenin signaling cascades in HCC requires further investigation.

\section{Role of STAT3 in regulation of apoptosis}

Constitutively activated STAT3 is found to participate in oncogenesis of the liver through up-regulation of STAT3-targeted genes 
Table 1

Selective list of pharmacological STAT3 inhibitors in HCC.

\begin{tabular}{|c|c|c|c|}
\hline Natural/synthetic Inhibitors & Mechanism of inhibition & Cell lines & Reference \\
\hline Celecoxib & Inhibits JAK2 phosphorylation & Hep3B, HepG2, HUH-7, SNU-387 and SNU-449 & {$[254]$} \\
\hline Parthenolide along with TRAIL & Inhibits activation of JAK proteins & HepG2, Hep3B and SK-Hep1 & {$[272]$} \\
\hline Galiellalactone & $\begin{array}{l}\text { STAT3 inhibitory effect by covalently modifying a cysteine } \\
\text { residue in the STAT3 DNA-binding domain }\end{array}$ & HepG2 & [273] \\
\hline $\mathrm{XZH}-5$ & $\begin{array}{l}\text { Reduced constitutive STAT3 phosphorylation at Tyr705 and } \\
\text { the expression of STAT3-regulated genes. }\end{array}$ & Hep3B, HepG2, HUH-7, SNU-387 and SNU-449 & [255] \\
\hline SD-1029 & Inhibits JAK/STAT3 pathway & Hep3B, SNU398, SNU-387, HepG2 and HUH-7 & {$[274]$} \\
\hline Sorafenib & SHP-1-dependent STAT3 inactivation. & PLC/PRF5, HUH-7, Hep3B and SK-Hep1 & [275] \\
\hline Soreafenib in combination with TRAIL & Upregulates SHP-1 activity & PLC/PRF5, HUH-7, Hep3B and Sk-Hep1 & [276] \\
\hline CADPE & $\begin{array}{l}\text { Inhibits both IL-6-mediated STAT3 activation and recruitment } \\
\text { of STAT3 to the cyclin D1 promoter. }\end{array}$ & HUH-7 & [277] \\
\hline FLL32 & $\begin{array}{l}\text { JAK/STAT inhibitor inhibits STAT3 phosphorylation, DNA } \\
\text { binding activities, and STAT3-regulated gene products. }\end{array}$ & SNU-449, SNU-398, HEp3B and SNU387 & [256] \\
\hline Diosgenin & $\begin{array}{l}\text { Induces the expression of Src homology } 2 \text { phosphatase } 2 \\
\text { (SH-PTP2) that correlate with down-regulation of } \\
\text { constitutive STAT3 activation }\end{array}$ & HepG2, C3A & [259] \\
\hline Butein & $\begin{array}{l}\text { Inhibits activation of upstream kinases c-Src, JAK2 and } \\
\text { induces the expression of SHP-1 }\end{array}$ & HepG2, SNU-387, HCCLM3 and PLC/PRF5 & [261] \\
\hline$\gamma$-tocotrienol & Increases the expression of SHP- 1 in HCC cells & HepG2 and HUH-7 & {$[262]$} \\
\hline$\beta$-escin & Inhibits activation of upstream kinases c-Src, JAK1, and JAK2. & HepG2, HUH-7, PLC/PRF5 & {$[260]$} \\
\hline NSC 74859 & TGF- $\beta$ signaling & $\begin{array}{l}\text { HepG2, PLC/PRF/5, HUH-7, SNU-398,SNU-449, } \\
\text { SNU-182 and SNU-475 }\end{array}$ & [6] \\
\hline 17-Hydroxy-jolkinolide B (HJB) & $\begin{array}{l}\text { HJB reacts with cysteine residues of JAKs to form covalent } \\
\text { bonds that inactivate JAKs. }\end{array}$ & HepG2 & {$[278]$} \\
\hline ENMD-1198 & Inhibits STAT3 phosphorylation & HUH-7 and HepG2 & [257] \\
\hline AG490 & Janus kinase 2 specific inhibitor & HUH-1, HUH-7, HepG2 and Hep3B & {$[224]$} \\
\hline IL-6-RFP & A high affinity cytokine-binding protein & HepG2 & [279] \\
\hline YC-1 & $\begin{array}{l}\text { Inhibits STAT3 activity by enhancing the polyubiquitination } \\
\text { of p-STAT3(705) induced by cisplatin }\end{array}$ & HepG2, Hep3B and PLC/PRF/5 & {$[280]$} \\
\hline Atiprimod & $\begin{array}{l}\text { Suppresses STAT3-mediated through the inhibition of } \\
\text { activation of upstream kinases c-Src, JAK1 and JAK2 }\end{array}$ & HUH-7 and HepG2 & [281] \\
\hline Antisense oligonucleotide & $\begin{array}{l}\text { Suppression of phosphorylated STAT3 reduced its } \\
\text { DNA-binding activity }\end{array}$ & HCCLM3, SNU423, HUH-7 and HCCLM3 & [195] \\
\hline Stattic & Inhibit SH2 domain, STAT3 dimerization and DNA binding. & HepG2 & [271] \\
\hline Luteolin & $\begin{array}{l}\text { Accelerated ubiquitin-dependent degradation in the } \\
\text { Tyr705-phosphorylated STAT3 }\end{array}$ & HepG2, HLF and HAK-1B & [282] \\
\hline Statins & Statins reduced IL-6-induced serine phosphorylation of STAT3. & Нер3в & [283] \\
\hline $\begin{array}{l}\text { 2-(1-chloropropenyl)-4, } \\
\text { 5-dihydroxy-cyclopent-2-enone }\end{array}$ & $\begin{array}{l}\text { Suppresses IL-6-dependent pathway by inhibiting the } \\
\text { tyrosine phosphorylation of STAT3 as well as the serine } \\
\text { phosphorylation of the STAT3 by direct inhibition of JAK. }\end{array}$ & HepG2 & [270] \\
\hline
\end{tabular}

encoding apoptosis inhibitors, e.g., Bcl-2, Bcl-xL, and survivin, $M c l-1$, $X I A P$, and subsequently inhibiting pro-apoptotic molecules such as Bax, Bad and Bid [81,189]. For example, STAT3 activation can support tumor cell survival through up-regulating the expression of the $\mathrm{Bcl}-\mathrm{xL}$. In fact, Bcl-xL was the first antiapoptotic factor shown to be regulated by STAT3 [216,217]. Mcl-1 is another anti-apoptotic gene of the Bcl-2 family that is a target of both STAT3 and STAT5. Blocking either of these STAT proteins in human tumor cells has been shown to downregulate Mcl-1 expression and can induces apoptosis [218].

Of all inhibitor of apoptosis (IAP), X-linked inhibitor of apoptosis (XIAP) is a principal inhibitor of apoptosis through its ability to inhibit caspase- 3 and caspase-7, particularly in HCC cells. XIAP is constitutively expressed in all HCC cell lines and in approximately 70\% of HCC tissue [219], whereas little or no expression is seen in chronic hepatitis or cirrhotic tissue [220]. Among the members of the IAP family, survivin is particularly highly expressed in various types of human cancers, including HCC [132,221]. Survivin is expressed at high levels in HCC and is regulated by STAT3 [222,223]. In vitro and in vivo investigations have also revealed that the application of STAT3 decoy ODN of the sequence of 5'CATTTCCCGTAAATC-3' can significantly block STAT3-dependent transcription of such genes as cyclin D1, c-Myc, Bcl-xL, and survivin, leading to reduced proliferation and induction of apoptosis in HCC cells [224].

\section{Role of STAT3 in cell cycle progression}

The expression of cyclin D1, which can associate with cdk4 or cdk6 and controls progression from G1 to S phase, is elevated in STAT3-C expressing cells [203]. Previous studies have also indicated a role for STAT3 in the $\mathrm{G} 1$ to $\mathrm{S}$ phase transition, mediated by the gp130 receptor subunit. Since STAT3-C possesses oncogenic potential, it is possible that STAT3-mediated transcriptional regulation of key components of cell cycle control contributes to malignant progression by promoting inappropriate cell cycle traversal [120]. Interestingly, at the peak of $S$ phase, which is approximately $40 \mathrm{~h}$ post-hepatectomy in mouse livers, the percentage of hepatocytes undergoing DNA synthesis is 5-fold lower in IL-6 - / - livers than IL-6 +/+ livers, whereas the difference between the Alb + and Alb- STAT3 $\mathrm{fl} / \mathrm{fl}$ livers is smaller at about 3-fold [150]. Thus the regulation of cyclin D1 expression is critical for the proliferation and differentiation of hepatocytes. Recent studies have indicated that inappropriate expression of cell cycle-related proteins, such as cyclin D1, cyclin-dependent kinase 4 (Cdk4), cyclin E, cyclin A, p16 and $\mathrm{p} 27$, as one of the major factors contributing to HCC initiation and development [225-227]. Moreover, Cressman et al. found that IL-6-deficient mice exhibit defects in STAT3 activation and in cyclin D1 induction after partial hepatectomy [63]. Therefore, it is likely that STAT3 can act as a potential negative regulator of cyclin D1 transcription during fetal liver development, whereas it positively regulates cyclin D1 expression in hepatoma cells and at the initial phase of liver regeneration. These findings clearly indicate that cyclin D1 gene is an important target of STAT3 in hepatocytes and that its regulation by STAT3 varies, depending on the cell stage, i.e. proliferation or differentiation.

\section{Role of STAT3 in angiogenesis}

Angiogenesis, considered as one of the ten hallmarks of cancer is required not only for tumor growth at primary sites but also for 
continued tumor growth at metastatic sites [228]. During organogenesis, all cells in a tissue must reside within close proximity of a capillary [229]. Similarly, most tumors cannot sustain their growth unless they are supplied with oxygen and nutrients from newly formed blood vessels, and a crucial role of activated oncogene products in stimulating angiogenesis has been established [230]. The most potent angiogenesis-inducing signal identified so far is vascular endothelial growth factor (VEGF) [231-235]. Compared with their normal counterparts, cancer cells produce increased levels of VEGF, which binds to transmembrane receptor tyrosine kinases of endothelial cells [230]. This activates endothelial-cell migration and proliferation, which is necessary for the formation of new blood vessels [230,231]. Activated STAT3 affects tumor angiogenesis by regulating the expression of multiple pro-angiogenic molecules in tumor cells and by participating in the signal transduction of angiogenic molecule receptors in tumor endothelial cells. Hepatocellular cancer is notable for its highly aggressive behavior, hypervascularity, portal and hepatic vein invasion and metastasis [236-238]. Aberrant VEGF expression is a prominent clinical feature in HCC and may correlate with HCC tumor invasion and metastasis [239]. It has been observed that STAT3 can also regulate the expression of other angiogenic molecules, such as basic FGF (bFGF) [133] which participates in angiogenesis by inducing the migration, proliferation, and differentiation of endothelial cells and by regulating VEGF expression in tumor cells in an autocrine and paracrine fashion [240]. It is widely believed that the ability of PDGFs to induce liver fibrosis and neoplastic cell transformation is closely associated with the transcriptional induction of TGF $\beta$, an essential mediator of fibrogenesis [241,242]. TGF $\beta$ and PDGFs act through activation of STAT3 $[75,76]$ leading to the upregulation of genes promoting cell proliferation, survival, and cell transformation [77]. The role of TGF 3 and PDGF pathways in the induction of liver fibrosis and cirrhosis, and putative contributing events to the neoplastic transformation of hepatocytes [243-246] is well established. In addition, STAT3 also regulates the transcription of VEGF indirectly by controlling the expression of hypoxiainducible factor (HIF)-1, a key inducible transcription factor for the VEGF gene [84].

\section{Role of STAT3 in cellular invasion}

Recent studies have linked STAT3 to metastatic progression of liver cancer [195]. Contribution of STAT3 to metastatic progression of liver cancers occurs through a variety of molecular mechanisms [53]. For example, STAT3 activation regulates the expression of matrix metalloproteinases MMP-2 and MMP-1, which then mediate tumor invasion and metastasis [133]. Moreover, a number of studies using mouse embryo fibroblasts as the model system established STAT3 as a component of the Rho GTPase-signaling cascade and an effector of cell migration via regulation of actin cytoskeleton [247-250]. Recent results from gene profiling analysis indicate that the expression signature of primary HCC is very similar to that of its corresponding metastases, suggesting that transcriptional changes which control metastatic progression are initiated in the primary tumors [251]. STAT3 however, is also known to upregulate tissue inhibitors of metalloproteinase TIMP-1, a cytokine known to block metalloproteinases and decrease invasiveness in certain cancer cell types [252]. STAT3 also controls the expression of the MUC1 gene, which can mediate tumor invasion [253]. Interestingly, the malignant development of HCCLM3 tumors orthotopically implanted in athymic mice prior was effectively inhibited, including inhibition of tumor growth, local transmission, and lung metastasis, resulting in significantly prolonged survival time upon treatment with STAT3 antisense oligonucleotide [195]. Thus, it is clear that STAT3 signaling plays a key role in HCC invasion and metastasis, and that targeting STAT3 may have therapeutic benefit for patients with primary or recurrent HCC.

\section{Pharmacological inhibition of STAT3 activation pathway in HCC}

Numerous studies as described above have validated the critical role of aberrant STAT3 activity in malignant transformation and tumor progression in HCC [65,254-256]. Since constitutive activation of STAT3 has also been reported in a number of hematological neoplasias, as well as in solid tumors other than HCC, STAT3 protein has emerged as a promising molecular target for the treatment of cancer [257]. Natural agents, peptides, platinum compounds and other small molecules have been used to inhibit STAT3 activity in various tumor models including HCC [258]. Our group has identified number of STAT3 inhibitors including diosgenin, $\beta$-escin, $\gamma$-tocotrienol, butein, honokiol, and celastrol that can suppress growth and induce apoptosis in diverse HCC cell lines [259-264]. In addition, Chen and coworkers recently reported that a novel obatoclax derivative, SC-2001, can induce apoptosis in hepatocellular carcinoma cells through SHP-1-dependent STAT3 inactivation [265]. Sorafenib has already been reported to inhibit both the growth and metastasis of HCC by blocking STAT3 activation [266].

Moreover, another multikinase inhibitor Dovitinib has been found to induce apoptosis and overcome sorafenib resistance in HCC through SHP-1-mediated inhibition of STAT3 [267]. Additionally, STAT3 inhibitor NSC74859 has been found to be greatly effective in HCC with disrupted TGF- $\beta$ signaling [6]. Also, oligonucleotide-based decoys of the STAT3 DNA-binding sequence have already entered clinical trials [268].

Furthermore, as discussed above, tumorigenesis induced by IL-6 has also been linked to constitutive or aberrant activation of STAT3 in various cancers, including HCC $[65,81,256,269]$. Thus, molecules which inhibit IL-6 or GP-130 receptor may act as good target for inhibition of STAT3 mediated tumorigenesis [65]. The necessity of an intact SH2 domain for optimal STAT3 activation also makes it a rational target for the disruption of STAT3 signaling [221]. Targeting the SH2 domain would uncouple STAT3 from the growth and survival signaling pathways and is a reasonable approach for the development of anticancer agents [270,271]. Also, targeting the upstream molecules of STAT3 such as JAKs and Src kinases can also be used as a strategy to block STAT3 activation [254,271]. However, ideal STAT3 inhibitors should not affect activation of other STAT proteins and should exhibit minimal side effects. Various natural and synthetic inhibitors of STAT3 targeting aberrant proliferation in HCC are described in Table 1.

\section{Conclusions}

A variety of animal models have been used to study the role of STAT3 signaling cascades in HCC development. In addition, most of our mechanistic understanding of STAT3 pathway in HCC comes from studies using cell type-specific knockout mice. STAT3 in these mice is knocked out only in specific cell types and remains functional in most other cell types. Thus, the results obtained may not precisely predict the effect of inhibitors that interfere with the activity of this transcription factors in cells that remain unaffected in knockout mice. Hence, the knowledge gained about STAT3 in HCC will depend on solutions to these potential problems. The current literature clearly indicates that STAT3 activation plays a major role in oncogenesis and that the suppression of STAT3 activation will pave the way for more effective treatment of HCC in near future. However, appropriate human studies are required to validate the promising results obtained in mice and move the STAT3 inhibitors from the bench side to the bed for the treatment of HCC patients.

\section{Acknowledgements}

This research work was supported by grants from the Singapore Ministry of Health's National Medical Research Council to GS under 
its Individual research grants funding scheme. APK was supported by grants from the National Medical Research Council of Singapore [Grant R-713-000-124-213] and Cancer Science Institute of Singapore, Experimental Therapeutics I Program [Grant R-713-001-011-271]. KMH was supported by grants from National Medical Research Council of Singapore, Biomedical Research Council of Singapore and the Singapore Millennium Foundation.

\section{References}

[1] N. Fausto, J.S. Campbell, K.J. Riehle, Liver regeneration, Hepatology 43 (2006) S45-S53.

[2] W.Y. Lau, E.C. Lai, Hepatocellular carcinoma: current management and recent advances, Hepatobiliary Pancreat. Dis. Int. 7 (2008) 237-257.

[3] S. Osada, S. Saji, T. Kuno, Clinical significance of combination study of apoptotic factors and proliferating cell nuclear antigen in estimating the prognosis of hepatocellular carcinoma, J. Surg. Oncol. 85 (2004) 48-54.

[4] F.X. Bosch, J. Ribes, M. Diaz, R. Cleries, Primary liver cancer: worldwide incidence and trends, Gastroenterology 127 (2004) S5-S16.

[5] T.M. Block, A.S. Mehta, C.J. Fimmel, R. Jordan, Molecular viral oncology of hepatocellular carcinoma, Oncogene 22 (2003) 5093-5107.

[6] L. Lin, R. Amin, G.I. Gallicano, E. Glasgow, W. Jogunoori, J.M. Jessup, M. Zasloff, J.L. Marshall, K. Shetty, L. Johnson, L. Mishra, A.R. He, The STAT3 inhibitor NSC 74859 is effective in hepatocellular cancers with disrupted TGF-beta signaling, Oncogene 28 (2009) 961-972.

[7] H.E. Blum, Hepatocellular carcinoma: therapy and prevention, World J. Gastroenterol. 11 (2005) 7391-7400.

[8] F. Bray, J. Ferlay, P. Pisani, D.M. Parkin, Cancer incidence, mortality and prevalence worldwide, in: J. Ferlay (Ed.), IARC press, Lyon, 2001.

[9] T.K. Seow, R.C. Liang, C.K. Leow, M.C. Chung, Hepatocellular carcinoma: from bedside to proteomics, Proteomics 1 (2001) 1249-1263.

[10] J.F. Wilson, Liver cancer on the rise, Ann. Intern. Med. 142 (2005) 1029-1032.

[11] Y. Nakamoto, S. Kaneko, Mechanisms of viral hepatitis induced liver injury, Curr. Mol. Med. 3 (2003) 537-544.

[12] K. Herzer, M.F. Sprinzl, P.R. Galle, Hepatitis viruses: live and let die, Liver Int. 27 (2007) 293-301.

[13] M.J. Tong, N.S. el-Farra, A.R. Reikes, R.L. Co, Clinical outcomes after transfusionassociated hepatitis C, N. Engl. J. Med. 332 (1995) 1463-1466.

[14] O. Hino, K. Kajino, T. Umeda, Y. Arakawa, Understanding the hypercarcinogenic state in chronic hepatitis: a clue to the prevention of human hepatocellular carcinoma, J. Gastroenterol. 37 (2002) 883-887.

[15] M.A. Feitelson, H.M. Reis, J. Liu, Z. Lian, J. Pan, Hepatitis B virus X antigen (HBxAg) and cell cycle control in chronic infection and hepatocarcinogenesis, Front. Biosci. 10 (2005) 1558-1572.

[16] M.J. Bouchard, R.J. Schneider, The enigmatic X gene of hepatitis B virus, J. Virol. 78 (2004) 12725-12734.

[17] A.S. Kekule, U. Lauer, L. Weiss, B. Luber, P.H. Hofschneider, Hepatitis B virus transactivator HBx uses a tumour promoter signalling pathway, Nature 361 (1993) 742-745.

[18] C.T. Yeh, C.H. Shen, D.I. Tai, C.M. Chu, Y.F. Liaw, Identification and characterization of a prevalent hepatitis B virus $\mathrm{X}$ protein mutant in Taiwanese patients with hepatocellular carcinoma, Oncogene 19 (2000) 5213-5220.

[19] C.C. Hsia, H. Yuwen, E. Tabor, Hot-spot mutations in hepatitis B virus X gene in hepatocellular carcinoma, Lancet 348 (1996) 625-626.

[20] S. Becker, B. Groner, C.W. Muller, Three-dimensional structure of the Stat3beta homodimer bound to DNA, Nature 394 (1998) 145-151.

[21] K. Abe, Y. Edamoto, Y.N. Park, A.M. Nomura, T.C. Taltavull, M. Tani, S.N. Thung, In situ detection of hepatitis B, C, and $\mathrm{G}$ virus nucleic acids in human hepatocellular carcinoma tissues from different geographic regions, Hepatology 28 (1998) 568-572.

[22] R. Beasley, Hepatitis B virus. The major etiology of hepatocelluar carcinoma, in: R.J. Fortner JC (Ed.) Accomplishment in Cancer Research 1987, JP Lippincot, 1988, Philadelphia, 1987.

[23] J. Dubuisson, F. Penin, D. Moradpour, Interaction of hepatitis C virus proteins with host cell membranes and lipids, Trends Cell Biol. 12 (2002) 517-523.

[24] C. Bureau, J. Bernad, N. Chaouche, C. Orfila, M. Beraud, C. Gonindard, L. Alric, J.P. Vinel, B. Pipy, Nonstructural 3 protein of hepatitis $C$ virus triggers an oxidative burst in human monocytes via activation of NADPH oxidase, J. Biol. Chem. 276 (2001) 23077-23083.

[25] G. Gong, G. Waris, R. Tanveer, A. Siddiqui, Human hepatitis C virus NS5A protein alters intracellular calcium levels, induces oxidative stress, and activates STAT-3 and NF-kappa B, Proc. Natl. Acad. Sci. U. S. A. 98 (2001) 9599-9604.

[26] L.R. Roberts, G.J. Gores, Hepatocellular carcinoma: molecular pathways and new therapeutic targets, Semin. Liver Dis. 25 (2005) 212-225.

[27] L.Y. Wang, C.J. Chen, Y.J. Zhang, W.Y. Tsai, P.H. Lee, M.A. Feitelson, C.S. Lee, R.M. Santella, 4-Aminobiphenyl DNA damage in liver tissue of hepatocellular carcinoma patients and controls, Am. J. Epidemiol. 147 (1998) 315-323.

[28] H.B. El-Serag, H. Hampel, F. Javadi, The association between diabetes and hepatocellular carcinoma: a systematic review of epidemiologic evidence, Clin. Gastroenterol. Hepatol. 4 (2006) 369-380.

[29] L.A. Adams, P. Angulo, Recent concepts in non-alcoholic fatty liver disease, Diabet. Med. 22 (2005) 1129-1133.

[30] S. Toffanin, S.L. Friedman, J.M. Llovet, Obesity, inflammatory signaling, and hepatocellular carcinoma-an enlarging link, Cancer Cell 17 (2010) 115-117.
[31] A.L. Fracanzani, D. Conte, M. Fraquelli, E. Taioli, M. Mattioli, A. Losco, S. Fargion, Increased cancer risk in a cohort of 230 patients with hereditary hemochromatosis in comparison to matched control patients with non-iron-related chronic liver disease, Hepatology 33 (2001) 647-651.

[32] M. Elmberg, R. Hultcrantz, A. Ekbom, L. Brandt, S. Olsson, R. Olsson, S. Lindgren, L. Loof, P. Stal, S. Wallerstedt, S. Almer, H. Sandberg-Gertzen, J. Askling, Cancer risk in patients with hereditary hemochromatosis and in their first-degree relatives, Gastroenterology 125 (2003) 1733-1741.

[33] M. Abdel-Wahab, N. El-Ghawalby, M. Mostafa, A. Sultan, M. El-Sadany, O. Fathy, T. Salah, F. Ezzat, Epidemiology of hepatocellular carcinoma in lower Egypt Mansoura Gastroenterology Center, Hepatogastroenterology 54 (2007) 157-162.

[34] G.S. Qian, R.K. Ross, M.C. Yu, J.M. Yuan, Y.T. Gao, B.E. Henderson, G.N. Wogan, J.D. Groopman, A follow-up study of urinary markers of aflatoxin exposure and liver cancer risk in Shanghai, People's Republic of China, Cancer Epidemiol. Biomarkers Prev. 3 (1994) 3-10.

[35] S.M. Thomas, J.S. Brugge, Cellular functions regulated by Src family kinases, Annu. Rev. Cell Dev. Biol. 13 (1997) 513-609.

[36] D. Thomas, Exagenous Steroid Hormones and Hepatocellular Carcinoma, in: A.D.B.E. Tabor, R.H. Purcell (Eds.), Etiology, Pathology and Treatment of Hepatocellular Carcinoma in North America, Gulf Publishing Company, Houston, 1991.

[37] K. Shuai, G.R. Stark, I.M. Kerr, J.E. Darnell Jr., A single phosphotyrosine residue of Stat91 required for gene activation by interferon-gamma, Science 261 (1993) 1744-1746.

[38] J.E. Darnell Jr., I.M. Kerr, G.R. Stark, Jak-STAT pathways and transcriptional activation in response to IFNs and other extracellular signaling proteins, Science 264 (1994) 1415-1421.

[39] X.S. Hou, N. Perrimon, The JAK-STAT pathway in Drosophila, Trends Genet. 13 (1997) 105-110.

[40] R. Yan, S. Small, C. Desplan, C.R. Dearolf, J.E. Darnell Jr., Identification of a Stat gene that functions in Drosophila development, Cell 84 (1996) 421-430.

[41] H. Ueno, K. Sasaki, K. Miyagawa, H. Honda, K. Mitani, Y. Yazaki, H. Hirai, Antisense repression of proto-oncogene c-Cbl enhances activation of the JAK-STAT pathway but not the ras pathway in epidermal growth factor receptor signaling J. Biol. Chem. 272 (1997) 8739-8743.

[42] C. Barillas-Mury, Y.S. Han, D. Seeley, F.C. Kafatos, Anopheles gambiae Ag-STAT, a new insect member of the STAT family, is activated in response to bacterial infection, EMBO J. 18 (1999) 959-967.

[43] A.C. Oates, P. Wollberg, S.J. Pratt, B.H. Paw, S.L. Johnson, R.K. Ho, J.H Postlethwait, L.I. Zon, A.F. Wilks, Zebrafish stat3 is expressed in restricted tissues during embryogenesis and stat1 rescues cytokine signaling in a STAT1-deficient human cell line, Dev. Dyn. 215 (1999) 352-370.

[44] M. Heim, Signal Transducers and Activators of Transcription (STATs): Activation and Biology, in: T. Hirano, P. Shegal (Eds.), The Stat protein family, vol. 2, Kluwer Academic Publishers, The Netherlands, 2003, pp. 11-26.

[45] J. Bromberg, Stat proteins and oncogenesis, J. Clin. Invest. 109 (2002) 1139-1142

[46] N.G. Copeland, D.J. Gilbert, C. Schindler, Z. Zhong, Z. Wen, J.E. Darnell Jr., A.L. Mui, A. Miyajima, F.W. Quelle, J.N. Ihle, et al., Distribution of the mammalian Stat gene family in mouse chromosomes, Genomics 29 (1995) 225-228.

[47] A. Strain, Liver growth and repair, Chapman and Hall, London, 1998.

[48] R. Taub, Hepatoprotection via the IL-6/Stat3 pathway, J. Clin. Invest. 112 (2003) 978-980.

[49] R.H. Costa, V.V. Kalinichenko, A.X. Holterman, X. Wang, Transcription factors in liver development, differentiation, and regeneration, Hepatology 38 (2003) 1331-1347.

[50] D. Mangnall, N.C. Bird, A.W. Majeed, The molecular physiology of liver regeneration following partial hepatectomy, Liver Int. 23 (2003) 124-138.

[51] U.M. Wegenka, J. Buschmann, C. Lutticken, P.C. Heinrich, F. Horn, Acute-phase response factor, a nuclear factor binding to acute-phase response elements, is rapidly activated by interleukin- 6 at the posttranslational level, Mol. Cell. Biol. 13 (1993) 276-288

[52] Z. Zhong, Z. Wen, J.E. Darnell Jr., Stat3: a STAT family member activated by tyrosine phosphorylation in response to epidermal growth factor and interleukin-6, Science 264 (1994) 95-98.

[53] B.B. Aggarwal, A.B. Kunnumakkara, K.B. Harikumar, S.R. Gupta, S.T. Tharakan, C. Koca, S. Dey, B. Sung, Signal transducer and activator of transcription-3, inflammation, and cancer: how intimate is the relationship? Ann. N. Y. Acad. Sci. 1171 (2009) 59-76.

[54] S. Akira, Y. Nishio, M. Inoue, X.J. Wang, S. Wei, T. Matsusaka, K. Yoshida, T. Sudo M. Naruto, T. Kishimoto, Molecular cloning of APRF, a novel IFN-stimulated gene factor 3 p91-related transcription factor involved in the gp130-mediated signaling pathway, Cell 77 (1994) 63-71.

[55] M. Hibi, M. Murakami, M. Saito, T. Hirano, T. Taga, T. Kishimoto, Molecular cloning and expression of an IL-6 signal transducer, gp130, Cell 63 (1990) 1149-1157.

[56] T. Hirano, K. Nakajima, M. Hibi, Signaling mechanisms through gp130: a model of the cytokine system, Cytokine Growth Factor Rev. 8 (1997) 241-252.

[57] N. Stahl, T.J. Farruggella, T.G. Boulton, Z. Zhong, J.E. Darnell Jr., G.D. Yancopoulos, Choice of STATs and other substrates specified by modular tyrosine-based motifs in cytokine receptors, Science 267 (1995) 1349-1353.

[58] H. Tilg, A. Wilmer, W. Vogel, M. Herold, B. Nolchen, G. Judmaier, C. Huber, Serum levels of cytokines in chronic liver diseases, Gastroenterology 103 (1992) 264-274

[59] M. Trikha, R. Corringham, B. Klein, J.F. Rossi, Targeted anti-interleukin-6 monoclonal antibody therapy for cancer: a review of the rationale and clinical evidence, Clin. Cancer Res. 9 (2003) 4653-4665.

[60] W.E. Naugler, T. Sakurai, S. Kim, S. Maeda, K. Kim, A.M. Elsharkawy, M. Karin, Gender disparity in liver cancer due to sex differences in MyD88-dependent IL-6 production, Science 317 (2007) 121-124. 
[61] K. Kovalovich, R.A. DeAngelis, W. Li, E.E. Furth, G. Ciliberto, R. Taub, Increased toxin-induced liver injury and fibrosis in interleukin-6-deficient mice, Hepatology 31 (2000) 149-159.

[62] S. Haga, K. Terui, H.Q. Zhang, S. Enosawa, W. Ogawa, H. Inoue, T. Okuyama, K Takeda, S. Akira, T. Ogino, K. Irani, M. Ozaki, Stat3 protects against Fas-induced liver injury by redox-dependent and -independent mechanisms, J. Clin. Invest. 112 (2003) 989-998.

[63] D.E. Cressman, L.E. Greenbaum, R.A. DeAngelis, G. Ciliberto, E.E. Furth, V. Poli, R. Taub, Liver failure and defective hepatocyte regeneration in interleukin-6deficient mice, Science 274 (1996) 1379-1383.

[64] C. Porta, M. De Amici, S. Quaglini, C. Paglino, F. Tagliani, A. Boncimino, R. Moratti, G.R. Corazza, Circulating interleukin-6 as a tumor marker for hepatocellular carcinoma, Ann. Oncol. 19 (2008) 353-358.

[65] Y. Liu, P.K. Li, C. Li, J. Lin, Inhibition of STAT3 signaling blocks the anti-apoptotic activity of IL-6 in human liver cancer cells, J. Biol. Chem. 285 (2010) 27429-27439.

[66] T. Alonzi, D. Maritano, B. Gorgoni, G. Rizzuto, C. Libert, V. Poli, Essential role of STAT3 in the control of the acute-phase response as revealed by inducible gene inactivation [correction of activation] in the liver, Mol. Cell. Biol. 21 (2001) 1621-1632.

[67] L. Dumoutier, E. Van Roost, D. Colau, J.C. Renauld, Human interleukin-10-related T cell-derived inducible factor: molecular cloning and functional characterization as an hepatocyte-stimulating factor, Proc. Natl. Acad. Sci. U. S. A. 97 (2000) 10144-10149.

[68] S. Radaeva, R. Sun, H.N. Pan, F. Hong, B. Gao, Interleukin 22 (IL-22) plays a protective role in T cell-mediated murine hepatitis: IL-22 is a survival factor for hepatocytes via STAT3 activation, Hepatology 39 (2004) 1332-1342.

[69] M.L. Vignais, H.B. Sadowski, D. Watling, N.C. Rogers, M. Gilman, Platelet-derived growth factor induces phosphorylation of multiple JAK family kinases and STAT proteins, Mol. Cell. Biol. 16 (1996) 1759-1769.

[70] U. Novak, A.G. Harpur, L. Paradiso, V. Kanagasundaram, A. Jaworowski, A.F. Wilks, J.A. Hamilton, Colony-stimulating factor 1-induced STAT1 and STAT3 activation is accompanied by phosphorylation of Tyk2 in macrophages and Tyk2 and JAK1 in fibroblasts, Blood 86 (1995) 2948-2956.

[71] M.B. Marrero, B. Schieffer, W.G. Paxton, L. Heerdt, B.C. Berk, P. Delafontaine, K.E Bernstein, Direct stimulation of Jak/STAT pathway by the angiotensin II AT1 receptor, Nature 375 (1995) 247-250.

[72] I. Guillet-Deniau, A.F. Burnol, J. Girard, Identification and localization of a skeletal muscle secrotonin 5-HT2A receptor coupled to the Jak/STAT pathway, J. Biol. Chem. 272 (1997) 14825-14829.

[73] T. Welte, D. Leitenberg, B.N. Dittel, B.K. al-Ramadi, B. Xie, Y.E. Chin, C.A Janeway Jr., A.L. Bothwell, K. Bottomly, X.Y. Fu, STAT5 interaction with the T cell receptor complex and stimulation of $\mathrm{T}$ cell proliferation, Science 283 (1999) 222-225.

[74] J.G. Karras, Z. Wang, L. Huo, D.A. Frank, T.L. Rothstein, Induction of STAT protein signaling through the CD40 receptor in B lymphocytes: distinct STAT activation following surface Ig and CD40 receptor engagement, J. Immunol. 159 (1997) 4350-4355.

[75] C. Sachsenmaier, H.B. Sadowski, J.A. Cooper, STAT activation by the PDGF receptor requires juxtamembrane phosphorylation sites but not Src tyrosine kinase activation, Oncogene 18 (1999) 3583-3592.

[76] Y.Z. Wang, W. Wharton, R. Garcia, A. Kraker, R. Jove, W.J. Pledger, Activation of Stat3 preassembled with platelet-derived growth factor beta receptors requires Src kinase activity, Oncogene 19 (2000) 2075-2085.

[77] D.E. Levy, J.E. Darnell Jr., Stats: transcriptional control and biological impact, Nat. Rev. Mol. Cell Biol. 3 (2002) 651-662.

[78] S.S. Thorgeirsson, J.W. Grisham, Molecular pathogenesis of human hepatocellular carcinoma, Nat. Genet. 31 (2002) 339-346.

[79] L. Libbrecht, V. Desmet, T. Roskams, Preneoplastic lesions in human hepatocarcinogenesis, Liver Int. 25 (2005) 16-27.

[80] Y.H. Lee, Y. Yun, HBx protein of hepatitis B virus activates Jak1-STAT signaling, J. Biol. Chem. 273 (1998) 25510-25515.

[81] D. Germain, D.A. Frank, Targeting the cytoplasmic and nuclear functions of signal transducers and activators of transcription 3 for cancer therapy, Clin. Cancer Res. 13 (2007) 5665-5669.

[82] U. Vinkemeier, I. Moarefi, J.E. Darnell Jr., J. Kuriyan, Structure of the amino-termina protein interaction domain of STAT-4, Science 279 (1998) 1048-1052.

[83] S. John, U. Vinkemeier, E. Soldaini, J.E. Darnell Jr., W.J. Leonard, The significance of tetramerization in promoter recruitment by Stat5, Mol. Cell. Biol. 19 (1999) 1910-1918.

[84] Q. Xu, J. Briggs, S. Park, G. Niu, M. Kortylewski, S. Zhang, T. Gritsko, J. Turkson, H. Kay, G.L. Semenza, J.Q. Cheng, R. Jove, H. Yu, Targeting Stat3 blocks both HIF-1 and VEGF expression induced by multiple oncogenic growth signaling pathways, Oncogene 24 (2005) 5552-5560.

[85] R.G. Collum, S. Brutsaert, G. Lee, C. Schindler, A Stat3-interacting protein (StIP1) regulates cytokine signal transduction, Proc. Natl. Acad. Sci. U. S. A. 97 (2000) 10120-10125.

[86] T. Zhang, K.T. Seow, C.T. Ong, X. Cao, Interdomain interaction of Stat3 regulates its Src homology 2 domain-mediated receptor binding activity, J. Biol. Chem. 277 (2002) 17556-17563.

[87] C.M. Horvath, STAT proteins and transcriptional responses to extracellular sig nals, Trends Biochem. Sci. 25 (2000) 496-502.

[88] J. Ma, X. Cao, Regulation of Stat3 nuclear import by importin alpha5 and importin alpha7 via two different functional sequence elements, Cell. Signal. 18 (2006) 1117-1126.

[89] K. Shuai, The STAT family of proteins in cytokine signaling, Prog. Biophys. Mol. Biol. 71 (1999) 405-422.
[90] B.G. Neel, N.K. Tonks, Protein tyrosine phosphatases in signal transduction, Curr. Opin. Cell Biol. 9 (1997) 193-204.

[91] K. Imada, W.J. Leonard, The Jak-STAT pathway, Mol. Immunol. 37 (2000) 1-11.

[92] S.G. Rane, E.P. Reddy, JAKs, STATs and Src kinases in hematopoiesis, Oncogene 21 (2002) 3334-3358.

[93] S. Pellegrini, I. Dusanter-Fourt, The structure, regulation and function of the Janus kinases (JAKs) and the signal transducers and activators of transcription (STATs), Eur. J. Biochem. 248 (1997) 615-633.

[94] C.M. Hilkens, H. Is'harc, B.F. Lillemeier, B. Strobl, P.A. Bates, I. Behrmann, I.M. Kerr, A region encompassing the FERM domain of Jak1 is necessary for binding to the cytokine receptor gp130, FEBS Lett. 505 (2001) 87-91.

[95] Y.J. Zhou, M. Chen, N.A. Cusack, L.H. Kimmel, K.S. Magnuson, J.G. Boyd, W. Lin, J.L Roberts, A. Lengi, R.H. Buckley, R.L. Geahlen, F. Candotti, M. Gadina, P.S. Changelian, J.J. O'Shea, Unexpected effects of FERM domain mutations on catalytic activity of Jak3: structural implication for Janus kinases, Mol. Cell 8 (2001) 959-969.

[96] D.G. Higgins, J.D. Thompson, T.J. Gibson, Using CLUSTAL for multiple sequence alignments, Methods Enzymol. 266 (1996) 383-402.

[97] D. Kampa, J. Burnside, Computational and functional analysis of the putative SH2 domain in Janus Kinases, Biochem. Biophys. Res. Commun. 278 (2000) 175-182.

[98] C. Haan, S. Kreis, C. Margue, I. Behrmann, Jaks and cytokine receptors-an intimate relationship, Biochem. Pharmacol. 72 (2006) 1538-1546.

[99] M.F. Richter, G. Dumenil, G. Uze, M. Fellous, S. Pellegrini, Specific contribution of Tyk2 JH regions to the binding and the expression of the interferon alpha/beta receptor component IFNAR1, J. Biol. Chem. 273 (1998) 24723-24729.

[100] C. Haan, P.C. Heinrich, I. Behrmann, Structural requirements of the interleukin-6 signal transducer gp130 for its interaction with Janus kinase 1: the receptor is crucial for kinase activation, Biochem. J. 361 (2002) 105-111.

101] M.C. Gauzzi, G. Barbieri, M.F. Richter, G. Uze, L. Ling, M. Fellous, S. Pellegrini, The amino-terminal region of Tyk2 sustains the level of interferon alpha receptor 1 , a component of the interferon alpha/beta receptor, Proc. Natl. Acad. Sci. U. S. A. 94 (1997) 11839-11844.

[102] J. Ragimbeau, E. Dondi, A. Alcover, P. Eid, G. Uze, S. Pellegrini, The tyrosine kinase Tyk2 controls IFNAR1 cell surface expression, EMBO J. 22 (2003) 537-547.

[103] L.J. Huang, S.N. Constantinescu, H.F. Lodish, The N-terminal domain of Janus kinase 2 is required for Golgi processing and cell surface expression of erythropoietin receptor, Mol. Cell 8 (2001) 1327-1338.

[104] S.J. Rodig, M.A. Meraz, J.M. White, P.A. Lampe, J.K. Riley, C.D. Arthur, K.L. King, K.C. Sheehan, L. Yin, D. Pennica, E.M. Johnson Jr., R.D. Schreiber, Disruption of the Jak1 gene demonstrates obligatory and nonredundant roles of the Jaks in cytokine-induced biologic responses, Cell 93 (1998) 373-383.

[105] T. Nosaka, J.M. van Deursen, R.A. Tripp, W.E. Thierfelder, B.A. Witthuhn, A.P. McMickle, P.C. Doherty, G.C. Grosveld, J.N. Ihle, Defective lymphoid development in mice lacking Jak3, Science 270 (1995) 800-802.

[106] D.C. Thomis, C.B. Gurniak, E. Tivol, A.H. Sharpe, L.J. Berg, Defects in B lymphocyte maturation and $\mathrm{T}$ lymphocyte activation in mice lacking Jak3, Science 270 (1995) 794-797.

[107] M.T. Brown, J.A. Cooper, Regulation, substrates and functions of src, Biochim. Biophys. Acta 1287 (1996) 121-149.

[108] J. Turkson, T. Bowman, R. Garcia, E. Caldenhoven, R.P. De Groot, R. Jove, Stat3 activation by Src induces specific gene regulation and is required for cell transformation, Mol. Cell. Biol. 18 (1998) 2545-2552.

[109] G.S. Martin, The hunting of the Src, Nat. Rev. Mol. Cell Biol. 2 (2001) 467-475.

[110] Z. Weng, S.M. Thomas, R.J. Rickles, J.A. Taylor, A.W. Brauer, C. Seidel-Dugan, W.M. Michael, G. Dreyfuss, J.S. Brugge, Identification of Src, Fyn, and Lyn SH3-binding proteins: implications for a function of SH3 domains, Mol. Cell. Biol. 14 (1994) 4509-4521.

[111] S.D. Briggs, S.S. Bryant, R. Jove, S.D. Sanderson, T.E. Smithgall, The Ras GTPase-activating protein (GAP) is an SH3 domain-binding protein and substrate for the Src-related tyrosine kinase, Hck, J. Biol. Chem. 270 (1995) $14718-14724$.

[112] G. Superti-Furga, S. Fumagalli, M. Koegl, S.A. Courtneidge, G. Draetta, Csk inhibition of c-Src activity requires both the SH2 and SH3 domains of Src, EMBO J. 12 (1993) 2625-2634.

[113] S.M. Murphy, M. Bergman, D.O. Morgan, Suppression of c-Src activity by C-terminal Src kinase involves the c-Src SH2 and SH3 domains: analysis with Saccharomyces cerevisiae, Mol. Cell. Biol. 13 (1993) 5290-5300.

[114] M. Okada, B.W. Howell, M.A. Broome, J.A. Cooper, Deletion of the SH3 domain of Src interferes with regulation by the phosphorylated carboxyl-terminal tyrosine, J. Biol. Chem. 268 (1993) 18070-18075.

[115] J. Kuriyan, D. Cowburn, Modular peptide recognition domains in eukaryotic signaling, Annu. Rev. Biophys. Biomol. Struct. 26 (1997) 259-288.

[116] G. Waksman, S.E. Shoelson, N. Pant, D. Cowburn, J. Kuriyan, Binding of a high affinity phosphotyrosyl peptide to the Src SH2 domain: crystal structures of the complexed and peptide-free forms, Cell 72 (1993) 779-790.

[117] M. Koegl, P. Zlatkine, S.C. Ley, S.A. Courtneidge, A.I. Magee, Palmitoylation of multiple Src-family kinases at a homologous N-terminal motif, Biochem. J. 303 (Pt 3) (1994) 749-753.

[118] M.D. Resh, Fatty acylation of proteins: new insights into membrane targeting of myristoylated and palmitoylated proteins, Biochim. Biophys. Acta 1451 (1999) $1-16$.

[119] J.M. Summy, Y. Qian, B.H. Jiang, A. Guappone-Koay, A. Gatesman, X. Shi, D.C. Flynn, The SH4-Unique-SH3-SH2 domains dictate specificity in signaling that differentiate c-Yes from c-Src, J. Cell Sci. 116 (2003) 2585-2598.

[120] T. Bowman, R. Garcia, J. Turkson, R. Jove, STATs in oncogenesis, Oncogene 19 (2000) 2474-2488. 
[121] N.C. Reich, L. Liu, Tracking STAT nuclear traffic, Nat. Rev. Immunol. 6 (2006) 602-612.

[122] J.N. Ihle, Cytokine receptor signalling, Nature 377 (1995) 591-594.

[123] C. Schindler, J.E. Darnell Jr., Transcriptional responses to polypeptide ligands: the JAK-STAT pathway, Annu. Rev. Biochem. 64 (1995) 621-651.

[124] M.P. Zeidler, E.A. Bach, N. Perrimon, The roles of the Drosophila JAK/STAT pathway, Oncogene 19 (2000) 2598-2606.

[125] T. Hirano, K. Ishihara, M. Hibi, Roles of STAT3 in mediating the cell growth, differentiation and survival signals relayed through the IL-6 family of cytokine receptors, Oncogene 19 (2000) 2548-2556

[126] T.E. Smithgall, S.D. Briggs, S. Schreiner, E.C. Lerner, H. Cheng, M.B. Wilson, Control of myeloid differentiation and survival by Stats, Oncogene 19 (2000) 2612-2618.

[127] A.L. Mui, The role of STATs in proliferation, differentiation, and apoptosis, Cell. Mol. Life Sci. 55 (1999) 1547-1558.

[128] R. Garcia, T.L. Bowman, G. Niu, H. Yu, S. Minton, C.A. Muro-Cacho, C.E. Cox, R Falcone, R. Fairclough, S. Parsons, A. Laudano, A. Gazit, A. Levitzki, A. Kraker, R. Jove, Constitutive activation of Stat 3 by the Src and JAK tyrosine kinases participates in growth regulation of human breast carcinoma cells, Oncogene 20 (2001) 2499-2513.

[129] V. Gouilleux-Gruart, F. Gouilleux, C. Desaint, J.F. Claisse, J.C. Capiod, J. Delobel, R. Weber-Nordt, I. Dusanter-Fourt, F. Dreyfus, B. Groner, L. Prin, STAT-related transcription factors are constitutively activated in peripheral blood cells from acute leukemia patients, Blood 87 (1996) 1692-1697.

[130] J.V. Alvarez, P.G. Febbo, S. Ramaswamy, M. Loda, A. Richardson, D.A. Frank, Identification of a genetic signature of activated signal transducer and activator of transcription 3 in human tumors, Cancer Res. 65 (2005) 5054-5062.

[131] M.B. Nilsson, R.R. Langley, I.J. Fidler, Interleukin-6, secreted by human ovarian carcinoma cells, is a potent proangiogenic cytokine, Cancer Res. 65 (2005) 10794-10800.

[132] N. Kanda, H. Seno, Y. Konda, H. Marusawa, M. Kanai, T. Nakajima, T. Kawashima, A. Nanakin, T. Sawabu, Y. Uenoyama, A. Sekikawa, M. Kawada, K. Suzuki, T. Kayahara, H. Fukui, M. Sawada, T. Chiba, STAT3 is constitutively activated and supports cell survival in association with survivin expression in gastric cancer cells, Oncogene 23 (2004) 4921-4929.

[133] T.X. Xie, F.J. Huang, K.D. Aldape, S.H. Kang, M. Liu, J.E. Gershenwald, K. Xie, R. Sawaya, S. Huang, Activation of stat3 in human melanoma promotes brain metastasis, Cancer Res. 66 (2006) 3188-3196.

[134] Z. Qiu, C. Huang, J. Sun, W. Qiu, J. Zhang, H. Li, T. Jiang, K. Huang, J. Cao, RNA interference-mediated signal transducers and activators of transcription 3 gene silencing inhibits invasion and metastasis of human pancreatic cancer cells, Cancer Sci. 98 (2007) 1099-1106.

[135] Y. Morita, T. Naka, Y. Kawazoe, M. Fujimoto, M. Narazaki, R. Nakagawa, H. Fukuyama, S. Nagata, T. Kishimoto, Signals transducers and activators of transcription (STAT)-induced STAT inhibitor-1 (SSI-1)/suppressor of cytokine signaling-1 (SOCS-1) suppresses tumor necrosis factor alpha-induced cell death in fibroblasts, Proc. Natl. Acad. Sci. U. S. A. 97 (2000) 5405-5410.

[136] A.M. Gamero, H.A. Young, R.H. Wiltrout, Inactivation of Stat3 in tumor cells: releasing a brake on immune responses against cancer? Cancer Cell 5 (2004) 111-112.

[137] P. Yue, J. Turkson, Targeting STAT3 in cancer: how successful are we? Expert Opin. Investig. Drugs 18 (2009) 45-56.

[138] J.N. Ihle, STATs: signal transducers and activators of transcription, Cell 84 (1996) 331-334.

[139] U. Hemmann, C. Gerhartz, B. Heesel, J. Sasse, G. Kurapkat, J. Grotzinger, A. Wollmer, Z. Zhong, J.E. Darnell Jr., L. Graeve, P.C. Heinrich, F. Horn, Differential activation of acute phase response factor/Stat3 and Stat1 via the cytoplasmic domain of the interleukin 6 signal transducer gp130. II. Src homology SH2 domains define the specificity of stat factor activation, J. Biol. Chem. 271 (1996) 12999-13007.

[140] G.B. Ehret, P. Reichenbach, U. Schindler, C.M. Horvath, S. Fritz, M. Nabholz, P. Bucher, DNA binding specificity of different STAT proteins. Comparison of in vitro specificity with natural target sites, J. Biol. Chem. 276 (2001) 6675-6688.

[141] Z. Wen, J.E. Darnell Jr., Mapping of Stat3 serine phosphorylation to a single residue (727) and evidence that serine phosphorylation has no influence on DNA binding of Stat1 and Stat3, Nucleic Acids Res. 25 (1997) 2062-2067.

[142] H. Yu, D. Pardoll, R. Jove, STATs in cancer inflammation and immunity: a leading role for STAT3, Nat. Rev. Cancer 9 (2009) 798-809.

[143] A. Herrmann, M. Vogt, M. Monnigmann, T. Clahsen, U. Sommer, S. Haan, V. Poli, P.C. Heinrich, G. Muller-Newen, Nucleocytoplasmic shuttling of persistently activated STAT3, J. Cell Sci. 120 (2007) 3249-3261.

[144] A.L. Pranada, S. Metz, A. Herrmann, P.C. Heinrich, G. Muller-Newen, Real time analysis of STAT3 nucleocytoplasmic shuttling, J. Biol. Chem. 279 (2004) 15114-15123.

[145] N. Sato, R. Tsuruma, S. Imoto, Y. Sekine, R. Muromoto, K. Sugiyama, T. Matsuda, Nuclear retention of STAT3 through the coiled-coil domain regulates its activity, Biochem. Biophys. Res. Commun. 336 (2005) 617-624.

[146] J. ten Hoeve, M. de Jesus Ibarra-Sanchez, Y. Fu, W. Zhu, M. Tremblay, M. David, K. Shuai, Identification of a nuclear Stat1 protein tyrosine phosphatase, Mol. Cell. Biol. 22 (2002) 5662-5668.

[147] K. Takeda, K. Noguchi, W. Shi, T. Tanaka, M. Matsumoto, N. Yoshida, T. Kishimoto, S. Akira, Targeted disruption of the mouse Stat3 gene leads to early embryonic lethality, Proc. Natl. Acad. Sci. U. S. A. 94 (1997) 3801-3804.

[148] T. Matsuda, T. Nakamura, K. Nakao, T. Arai, M. Katsuki, T. Heike, T. Yokota, STAT3 activation is sufficient to maintain an undifferentiated state of mouse embryonic stem cells, EMBO J. 18 (1999) 4261-4269.

[149] S. Akira, Roles of STAT3 defined by tissue-specific gene targeting, Oncogene 19 (2000) 2607-2611.

[150] W. Li, X. Liang, C. Kellendonk, V. Poli, R. Taub, STAT3 contributes to the mitogenic response of hepatocytes during liver regeneration, J. Biol. Chem. 277 (2002) 28411-28417.
[151] H. Inoue, W. Ogawa, M. Ozaki, S. Haga, M. Matsumoto, K. Furukawa, N. Hashimoto, Y. Kido, T. Mori, H. Sakaue, K. Teshigawara, S. Jin, H. Iguchi, R. Hiramatsu, D. LeRoith, K. Takeda, S. Akira, M. Kasuga, Role of STAT-3 in regulation of hepatic gluconeogenic genes and carbohydrate metabolism in vivo, Nat. Med. 10 (2004) 168-174.

[152] P.J. Hauser, D. Agrawal, J. Hackney, W.J. Pledger, STAT3 activation accompanies keratinocyte differentiation, Cell Growth Differ. 9 (1998) 847-855.

[153] K. Shimozaki, K. Nakajima, T. Hirano, S. Nagata, Involvement of STAT3 in the granulocyte colony-stimulating factor-induced differentiation of myeloid cells, J. Biol. Chem. 272 (1997) 25184-25189.

[154] C. Boccaccio, M. Ando, L. Tamagnone, A. Bardelli, P. Michieli, C. Battistini, P.M. Comoglio, Induction of epithelial tubules by growth factor HGF depends on the STAT pathway, Nature 391 (1998) 285-288.

[155] S. Sano, K.S. Chan, S. Carbajal, J. Clifford, M. Peavey, K. Kiguchi, S. Itami, B.J. Nickoloff, J. DiGiovanni, Stat3 links activated keratinocytes and immunocytes required for development of psoriasis in a novel transgenic mouse model, Nat. Med. 11 (2005) 43-49.

[156] S. Sano, S. Itami, K. Takeda, M. Tarutani, Y. Yamaguchi, H. Miura, K. Yoshikawa, S Akira, J. Takeda, Keratinocyte-specific ablation of Stat3 exhibits impaired skin remodeling, but does not affect skin morphogenesis, EMBO J. 18 (1999) 4657-4668.

[157] R.S. Chapman, P.C. Lourenco, E. Tonner, D.J. Flint, S. Selbert, K. Takeda, S. Akira, A.R. Clarke, C.J. Watson, Suppression of epithelial apoptosis and delayed mammary gland involution in mice with a conditional knockout of Stat3, Genes Dev. 13 (1999) 2604-2616

[158] K. Takeda, S. Akira, STAT family of transcription factors in cytokine-mediated biological responses, Cytokine Growth Factor Rev. 11 (2000) 199-207.

[159] J.Y. Yoo, D.L. Huso, D. Nathans, S. Desiderio, Specific ablation of Stat3beta distorts the pattern of Stat3-responsive gene expression and impairs recovery from endotoxic shock, Cell 108 (2002) 331-344.

[160] P.C. Heinrich, I. Behrmann, S. Haan, H.M. Hermanns, G. Muller-Newen, F. Schaper, Principles of interleukin (IL)-6-type cytokine signalling and its regulation, Biochem. J. 374 (2003) 1-20.

[161] J. Bromberg, J.E. Darnell Jr., The role of STATs in transcriptional control and their impact on cellular function, Oncogene 19 (2000) 2468-2473.

[162] M. Kubo, T. Hanada, A. Yoshimura, Suppressors of cytokine signaling and immunity, Nat. Immunol. 4 (2003) 1169-1176.

[163] K. Shuai, Modulation of STAT signaling by STAT-interacting proteins, Oncogene 19 (2000) 2638-2644.

[164] A. Yoshimura, T. Ohkubo, T. Kiguchi, N.A. Jenkins, D.J. Gilbert, N.G. Copeland, T. Hara, A. Miyajima, A novel cytokine-inducible gene CIS encodes an $\mathrm{SH} 2$-containing protein that binds to tyrosine-phosphorylated interleukin 3 and erythropoietin receptors, EMBO J. 14 (1995) 2816-2826.

[165] W.S. Alexander, D.J. Hilton, The role of suppressors of cytokine signaling (SOCS) proteins in regulation of the immune response, Annu. Rev. Immunol. 22 (2004) 503-529.

[166] R. Starr, T.A. Willson, E.M. Viney, L.J. Murray, J.R. Rayner, B.J. Jenkins, T.J. Gonda, W.S. Alexander, D. Metcalf, N.A. Nicola, D.J. Hilton, A family of cytokine-inducible inhibitors of signalling, Nature 387 (1997) 917-921.

[167] T.A. Endo, M. Masuhara, M. Yokouchi, R. Suzuki, H. Sakamoto, K. Mitsui, A Matsumoto, S. Tanimura, M. Ohtsubo, H. Misawa, T. Miyazaki, N. Leonor, T. Taniguchi, T. Fujita, Y. Kanakura, S. Komiya, A. Yoshimura, A new protein containing an SH2 domain that inhibits JAK kinases, Nature 387 (1997) 921-924

[168] T. Naka, M. Narazaki, M. Hirata, T. Matsumoto, S. Minamoto, A. Aono, N. Nishimoto, T. Kajita, T. Taga, K. Yoshizaki, S. Akira, T. Kishimoto, Structure and function of a new STAT-induced STAT inhibitor, Nature 387 (1997) 924-929.

[169] D.J. Hilton, R.T. Richardson, W.S. Alexander, E.M. Viney, T.A. Willson, N.S. Sprigg R. Starr, S.E. Nicholson, D. Metcalf, N.A. Nicola, Twenty proteins containing a C-terminal SOCS box form five structural classes, Proc. Natl. Acad. Sci. U. S. A. 95 (1998) 114-119.

[170] C. Bjorbaek, J.K. Elmquist, J.D. Frantz, S.E. Shoelson, J.S. Flier, Identification of SOCS-3 as a potential mediator of central leptin resistance, Mol. Cell 1 (1998) 619-625.

[171] C. Bjorbaek, K. El-Haschimi, J.D. Frantz, J.S. Flier, The role of SOCS-3 in leptin signaling and leptin resistance, J. Biol. Chem. 274 (1999) 30059-30065.

[172] V. Emilsson, J.R. Arch, R.P. de Groot, C.A. Lister, M.A. Cawthorne, Leptin treatment increases suppressors of cytokine signaling in central and peripheral tissues, FEBS Lett. 455 (1999) 170-174.

[173] M. Narazaki, M. Fujimoto, T. Matsumoto, Y. Morita, H. Saito, T. Kajita, K. Yoshizaki, T. Naka, T. Kishimoto, Three distinct domains of SSI-1/SOCS-1/JAB protein are required for its suppression of interleukin 6 signaling, Proc. Natl. Acad. Sci. U. S. A. 95 (1998) 13130-13134.

[174] T. Kamura, S. Sato, D. Haque, L. Liu, W.G. Kaelin Jr., R.C. Conaway, J.W. Conaway, The Elongin BC complex interacts with the conserved SOCS-box motif present in members of the SOCS, ras, WD-40 repeat, and ankyrin repeat families, Genes Dev. 12 (1998) 3872-3881.

[175] J.G. Zhang, A. Farley, S.E. Nicholson, T.A. Willson, L.M. Zugaro, R.J. Simpson, R.L. Moritz, D. Cary, R. Richardson, G. Hausmann, B.J. Kile, S.B. Kent, W.S. Alexander, D. Metcalf, D.J. Hilton, N.A. Nicola, M. Baca, The conserved SOCS box motif in suppressors of cytokine signaling binds to elongins $B$ and $C$ and may couple bound proteins to proteasomal degradation, Proc. Natl. Acad. Sci. U. S. A. 96 (1999) 2071-2076.

[176] S. Kamizono, T. Hanada, H. Yasukawa, S. Minoguchi, R. Kato, M. Minoguchi, K. Hattori, S. Hatakeyama, M. Yada, S. Morita, T. Kitamura, H. Kato, K. Nakayama, A. Yoshimura, The SOCS box of SOCS-1 accelerates ubiquitin-dependent proteolysis of TEL-JAK2, J. Biol. Chem. 276 (2001) 12530-12538. 
177] A. Sasaki, K. Inagaki-Ohara, T. Yoshida, A. Yamanaka, M. Sasaki, H. Yasukawa, A.E. Koromilas, A. Yoshimura, The N-terminal truncated isoform of SOCS3 translated from an alternative initiation AUG codon under stress conditions is stable due to the lack of a major ubiquitination site, Lys-6, J. Biol. Chem. 278 (2003) 2432-2436.

[178] J.S. Campbell, L. Prichard, F. Schaper, J. Schmitz, A. Stephenson-Famy, M.E. Rosenfeld, G.M. Argast, P.C. Heinrich, N. Fausto, Expression of suppressors of cytokine signaling during liver regeneration, J. Clin. Invest. 107 (2001) 1285-1292.

[179] H. Yoshikawa, K. Matsubara, G.S. Oian, P. Jackson, J.D. Groopman, J.E. Manning C.C. Harris, J.G. Herman, SOCS-1, a negative regulator of the JAK/STAT pathway, is silenced by methylation in human hepatocellular carcinoma and shows growth-suppression activity, Nat. Genet. 28 (2001) 29-35.

[180] Y. Niwa, H. Kanda, Y. Shikauchi, A. Saiura, K. Matsubara, T. Kitagawa, J. Yamamoto, T. Kubo, H. Yoshikawa, Methylation silencing of SOCS-3 promotes cell growth and migration by enhancing JAK/STAT and FAK signalings in human hepatocellular carcinoma, Oncogene 24 (2005) 6406-6417.

[181] T. Torisu, M. Nakaya, S. Watanabe, M. Hashimoto, H. Yoshida, T. Chinen, R. Yoshida, F. Okamoto, T. Hanada, K. Torisu, G. Takaesu, T. Kobayashi, H. Yasukawa, A Yoshimura, Suppressor of cytokine signaling 1 protects mice against concanavalin A-induced hepatitis by inhibiting apoptosis, Hepatology 47 (2008) 1644-1654.

[182] T.V. Bagnyukova, V.P. Tryndyak, L. Muskhelishvili, S.A. Ross, F.A. Beland, I.P. Pogribny, Epigenetic downregulation of the suppressor of cytokine signaling 1 (Socs1) gene is associated with the STAT3 activation and development of hepatocellular carcinoma induced by methyl-deficiency in rats, Cell Cycle 7 (2008) 3202-3210.

[183] P.K. Jackson, A new RING for SUMO: wrestling transcriptional responses into nuclear bodies with PIAS family E3 SUMO ligases, Genes Dev. 15 (2001) 3053-3058.

[184] K. Shuai, B. Liu, Regulation of gene-activation pathways by PIAS proteins in the immune system, Nat. Rev. Immunol. 5 (2005) 593-605.

[185] C.D. Chung, J. Liao, B. Liu, X. Rao, P. Jay, P. Berta, K. Shuai, Specific inhibition of Stat3 signal transduction by PIAS3, Science 278 (1997) 1803-1805.

[186] K. Shuai, B. Liu, Regulation of JAK-STAT signalling in the immune system, Nat. Rev. Immunol. 3 (2003) 900-911.

[187] D.F. Calvisi, S. Ladu, A. Gorden, M. Farina, E.A. Conner, J.S. Lee, V.M. Factor, S.S. Thorgeirsson, Ubiquitous activation of Ras and Jak/Stat pathways in human HCC, Gastroenterology 130 (2006) 1117-1128.

[188] C. Wu, Q. Guan, Y. Wang, Z.J. Zhao, G.W. Zhou, SHP-1 suppresses cancer cell growth by promoting degradation of JAK kinases, J. Cell. Biochem. 90 (2003) 1026-1037.

[189] K. Al Zaid Siddiquee, J. Turkson, STAT3 as a target for inducing apoptosis in solid and hematological tumors, Cell Res. 18 (2008) 254-267.

[190] X. Cao, A. Tay, G.R. Guy, Y.H. Tan, Activation and association of Stat3 with Src in v-Src-transformed cell lines, Mol. Cell. Biol. 16 (1996) 1595-1603.

[191] P. Chaturvedi, S. Sharma, E.P. Reddy, Abrogation of interleukin-3 dependence of myeloid cells by the v-src oncogene requires $\mathrm{SH} 2$ and $\mathrm{SH} 3$ domains which specify activation of STATs, Mol. Cell. Biol. 17 (1997) 3295-3304.

[192] J.F. Bromberg, C.M. Horvath, D. Besser, W.W. Lathem, J.E. Darnell Jr., Stat3 activation is required for cellular transformation by v-src, Mol. Cell. Biol. 18 (1998) 2553-2558.

[193] J.I. Song, J.R. Grandis, STAT signaling in head and neck cancer, Oncogene 19 (2000) 2489-2495.

[194] J.R. Grandis, S.D. Drenning, A. Chakraborty, M.Y. Zhou, Q. Zeng, A.S. Pitt, D.J. Tweardy, Requirement of Stat3 but not Stat1 activation for epidermal growth factor receptor- mediated cell growth In vitro, J. Clin. Invest. 102 (1998) 1385-1392.

[195] W.C. Li, S.L. Ye, R.X. Sun, Y.K. Liu, Z.Y. Tang, Y. Kim, J.G. Karras, H. Zhang, Inhibition of growth and metastasis of human hepatocellular carcinoma by antisense oligonucleotide targeting signal transducer and activator of transcription 3, Clin. Cancer Res. 12 (2006) 7140-7148.

[196] A. Tannapfel, K. Anhalt, P. Hausermann, F. Sommerer, M. Benicke, D. Uhlmann, H. Witzigmann, J. Hauss, C. Wittekind, Identification of novel proteins associated with hepatocellular carcinomas using protein microarrays, J. Pathol. 201 (2003) 238-249.

[197] D.Y. Feng, H. Zheng, Y. Tan, R.X. Cheng, Effect of phosphorylation of MAPK and Stat 3 and expression of c-fos and c-jun proteins on hepatocarcinogenesis and their clinical significance, World J. Gastroenterol. 7 (2001) 33-36.

[198] A. Sanchez, P. Nagy, S.S. Thorgeirsson, STAT-3 activity in chemically-induced hepatocellular carcinoma, Eur. J. Cancer 39 (2003) 2093-2098.

[199] U.P. Thorgeirsson, D.W. Dalgard, J. Reeves, R.H. Adamson, Tumor incidence in a chemical carcinogenesis study of nonhuman primates, Regul. Toxicol. Pharmacol. 19 (1994) 130-151.

[200] S. Rebouissou, M. Amessou, G. Couchy, K. Poussin, S. Imbeaud, C. Pilati, T. Izard C. Balabaud, P. Bioulac-Sage, J. Zucman-Rossi, Frequent in-frame somatic deletions activate gp130 in inflammatory hepatocellular tumours, Nature 457 (2009) 200-204

[201] S.F. Yang, S.N. Wang, C.F. Wu, Y.T. Yeh, C.Y. Chai, S.C. Chunag, M.C. Sheen, K.T. Lee, Altered p-STAT3 (tyr705) expression is associated with histological grading and intratumour microvessel density in hepatocellular carcinoma, J. Clin. Pathol. 60 (2007) 642-648.

[202] G.C. Yeoh, M. Ernst, S. Rose-John, B. Akhurst, C. Payne, S. Long, W. Alexander, B. Croker, D. Grail, V.B. Matthews, Opposing roles of gp130-mediated STAT-3 and ERK-1/ 2 signaling in liver progenitor cell migration and proliferation, Hepatology 45 (2007) 486-494.

[203] J.F. Bromberg, M.H. Wrzeszczynska, G. Devgan, Y. Zhao, R.G. Pestell, C. Albanese, J.E. Darnell Jr., Stat3 as an oncogene, Cell 98 (1999) 295-303.

[204] J. Zhou, J. Wulfkuhle, H. Zhang, P. Gu, Y. Yang, J. Deng, J.B. Margolick, L.A. Liotta, E. Petricoin III, Y. Zhang, Activation of the PTEN/mTOR/STAT3 pathway in breast cancer stem-like cells is required for viability and maintenance, Proc. Natl. Acad. Sci. U. S. A. 104 (2007) 16158-16163.
[205] G. He, G.Y. Yu, V. Temkin, H. Ogata, C. Kuntzen, T. Sakurai, W. Sieghart, M. Peck-Radosavljevic, H.L. Leffert, M. Karin, Hepatocyte IKKbeta/NF-kappaB inhibits tumor promotion and progression by preventing oxidative stress-driven STAT3 activation, Cancer Cell 17 (2010) 286-297.

[206] G. He, M. Karin, NF-kappaB and STAT3 - key players in liver inflammation and cancer, Cell Res. 21 (2011) 159-168.

[207] E. Pfitzner, S. Kliem, D. Baus, C.M. Litterst, The role of STATs in inflammation and inflammatory diseases, Curr. Pharm. Des. 10 (2004) 2839-2850.

[208] H. Lee, A. Herrmann, J.H. Deng, M. Kujawski, G. Niu, Z. Li, S. Forman, R. Jove, D.M. Pardoll, H. Yu, Persistently activated Stat3 maintains constitutive NF-kappaB activity in tumors, Cancer Cell 15 (2009) 283-293.

[209] N. Nadiminty, W. Lou, S.O. Lee, X. Lin, D.L. Trump, A.C. Gao, Stat3 activation of NF-\{kappa\}B p100 processing involves CBP/p300-mediated acetylation, Proc. Natl. Acad. Sci. U. S. A. 103 (2006) 7264-7269.

[210] S.I. Grivennikov, M. Karin, Dangerous liaisons: STAT3 and NF-kappaB collaboration and crosstalk in cancer, Cytokine Growth Factor Rev. 21 (2010) 11-19.

[211] S. Maeda, H. Kamata, J.L. Luo, H. Leffert, M. Karin, IKKbeta couples hepatocyte death to cytokine-driven compensatory proliferation that promotes chemical hepatocarcinogenesis, Cell 121 (2005) 977-990.

[212] C. Wang, W. Yang, H.X. Yan, T. Luo, J. Zhang, L. Tang, F.Q. Wu, H.L. Zhang, L.X. Yu, L.Y. Zheng, Y.Q. Li, W. Dong, Y.Q. He, Q. Liu, S.S. Zou, Y. Lin, L. Hu, Z. Li, M.C. Wu, H.Y. Wang, Hepatitis B virus X (HBx) induces tumorigenicity of hepatic progenitor cells in 3,5-diethoxycarbonyl-1,4-dihydrocollidine-treated HBx transgenic mice, Hepatology 55 (2012) 108-120.

[213] X.H. Wang, X. Sun, X.W. Meng, Z.W. Lv, Y.J. Du, Y. Zhu, J. Chen, D.X. Kong, S.Z. Jin, beta-catenin siRNA regulation of apoptosis- and angiogenesis-related gene expression in hepatocellular carcinoma cells: potential uses for gene therapy, Oncol. Rep. 24 (2010) 1093-1099.

[214] J. Ji, X.W. Wang, Clinical implications of cancer stem cell biology in hepatocellular carcinoma, Semin. Oncol. 39 (2012) 461-472.

[215] F. Yuan, W. Zhou, C. Zou, Z. Zhang, H. Hu, Z. Dai, Y. Zhang, Expression of Oct4 in HCC and modulation to wnt/beta-catenin and TGF-beta signal pathways, Mol. Cell. Biochem. 343 (2010) 155-162.

[216] R. Catlett-Falcone, T.H. Landowski, M.M. Oshiro, J. Turkson, A. Levitzki, R. Savino, G. Ciliberto, L. Moscinski, J.L. Fernandez-Luna, G. Nunez, W.S. Dalton, R. Jove, Constitutive activation of Stat3 signaling confers resistance to apoptosis in human U266 myeloma cells, Immunity 10 (1999) 105-115.

[217] G. Niu, R. Heller, R. Catlett-Falcone, D. Coppola, M. Jaroszeski, W. Dalton, R. Jove, $\mathrm{H}$. Yu, Gene therapy with dominant-negative Stat3 suppresses growth of the murine melanoma B16 tumor in vivo, Cancer Res. 59 (1999) 5059-5063.

[218] P.K. Epling-Burnette, J.H. Liu, R. Catlett-Falcone, J. Turkson, M. Oshiro, R. Kothapalli, Y. Li, J.M. Wang, H.F. Yang-Yen, J. Karras, R. Jove, T.P. Loughran Jr., Inhibition of STAT3 signaling leads to apoptosis of leukemic large granular lymphocytes and decreased Mcl-1 expression, J. Clin. Invest. 107 (2001) 351-362.

[219] H. Fuke, K. Shiraki, K. Sugimoto, J. Tanaka, T. Beppu, K. Yoneda, N. Yamamoto, K. Ito, M. Masuya, Y. Takei, Jak inhibitor induces S phase cell-cycle arrest and augments TRAIL-induced apoptosis in human hepatocellular carcinoma cells, Biochem. Biophys. Res. Commun. 363 (2007) 738-744

[220] K. Shiraki, K. Sugimoto, Y. Yamanaka, Y. Yamaguchi, Y. Saitou, K. Ito, N. Yamamoto, T. Yamanaka, K. Fujikawa, K. Murata, T. Nakano, Overexpression of $\mathrm{X}$-linked inhibitor of apoptosis in human hepatocellular carcinoma, Int. J. Mol. Med. 12 (2003) 705-708.

[221] N. Jing, D.J. Tweardy, Targeting Stat3 in cancer therapy, Anticancer Drugs 16 (2005) 601-607.

[222] T. Ito, K. Shiraki, K. Sugimoto, T. Yamanaka, K. Fujikawa, M. Ito, K. Takase, M. Moriyama, H. Kawano, M. Hayashida, T. Nakano, A. Suzuki, Survivin promotes cell proliferation in human hepatocellular carcinoma, Hepatology 31 (2000) 1080-1085.

[223] M.J. Duffy, N. O'Donovan, D.J. Brennan, W.M. Gallagher, B.M. Ryan, Survivin: a promising tumor biomarker, Cancer Lett. 249 (2007) 49-60.

[224] M. Kusaba, K. Nakao, T. Goto, D. Nishimura, H. Kawashimo, H. Shibata, Y. Motoyoshi, N. Taura, T. Ichikawa, K. Hamasaki, K. Eguchi, Abrogation of constitutive STAT3 activity sensitizes human hepatoma cells to TRAIL-mediated apoptosis, J. Hepatol. 47 (2007) 546-555.

[225] T. Masaki, Y. Shiratori, W. Rengifo, K. Igarashi, M. Yamagata, K. Kurokohchi, N. Uchida, Y. Miyauchi, H. Yoshiji, S. Watanabe, M. Omata, S. Kuriyama, Cyclins and cyclin-dependent kinases: comparative study of hepatocellular carcinoma versus cirrhosis, Hepatology 37 (2003) 534-543.

[226] Y. Matsuda, T. Ichida, T. Genda, S. Yamagiwa, Y. Aoyagi, H. Asakura, Loss of p16 contributes to 27 sequestration by cyclin $\mathrm{D}(1)$-cyclin-dependent kinase 4 complexes and poor prognosis in hepatocellular carcinoma, Clin. Cancer Res. 9 (2003) 3389-3396

[227] Y. Matsuda, T. Ichida, p16 and p27 are functionally correlated during the progress of hepatocarcinogenesis, Med. Mol. Morphol. 39 (2006) 169-175.

[228] J. Rak, J. Filmus, R.S. Kerbel, Reciprocal paracrine interactions between tumour cells and endothelial cells: the 'angiogenesis progression' hypothesis, Eur. J. Cancer 32A (1996) 2438-2450.

[229] J. Folkman, What is the evidence that tumors are angiogenesis dependent? J. Natl. Cancer Inst. 82 (1990) 4-6.

[230] T. Veikkola, K. Alitalo, VEGFs, receptors and angiogenesis, Semin. Cancer Biol. 9 (1999) 211-220.

[231] T. Veikkola, M. Karkkainen, L. Claesson-Welsh, K. Alitalo, Regulation of angiogenesis via vascular endothelial growth factor receptors, Cancer Res. 60 (2000) 203-212.

[232] D. Hanahan, J. Folkman, Patterns and emerging mechanisms of the angiogenic switch during tumorigenesis, Cell 86 (1996) 353-364. 
[233] I. Vivanco, C.L. Sawyers, The phosphatidylinositol 3-Kinase AKT pathway in human cancer, Nat. Rev. Cancer 2 (2002) 489-501.

[234] B. Millauer, L.K. Shawver, K.H. Plate, W. Risau, A. Ullrich, Glioblastoma growth inhibited in vivo by a dominant-negative Flk-1 mutant, Nature 367 (1994) 576-579.

[235] J. Grunstein, W.G. Roberts, O. Mathieu-Costello, D. Hanahan, R.S. Johnson, Tumor-derived expression of vascular endothelial growth factor is a critical factor in tumor expansion and vascular function, Cancer Res. 59 (1999) 1592-1598.

[236] R.T. Poon, I.O. Ng, C. Lau, W.C. Yu, S.T. Fan, J. Wong, Correlation of serum basic fibroblast growth factor levels with clinicopathologic features and postoperative recurrence in hepatocellular carcinoma, Am. J. Surg. 182 (2001) 298-304.

[237] T. Torimura, M. Sata, T. Ueno, M. Kin, R. Tsuji, K. Suzaku, O. Hashimoto, H. Sugawara, K. Tanikawa, Increased expression of vascular endothelial growth factor is associated with tumor progression in hepatocellular carcinoma, Hum. Pathol. 29 (1998) 986-991.

[238] H. Miura, T. Miyazaki, M. Kuroda, T. Oka, R. Machinami, T. Kodama, M. Shibuya, M. Makuuchi, Y. Yazaki, S. Ohnishi, Increased expression of vascular endothelial growth factor in human hepatocellular carcinoma, J. Hepatol. 27 (1997) 854-861.

[239] O.N. El-Assal, A. Yamanoi, Y. Soda, M. Yamaguchi, M. Igarashi, A. Yamamoto, T. Nabika, N. Nagasue, Clinical significance of microvessel density and vascular endothelial growth factor expression in hepatocellular carcinoma and surrounding liver: possible involvement of vascular endothelial growth factor in the angiogenesis of cirrhotic liver, Hepatology 27 (1998) 1554-1562.

[240] E. Devarajan, S. Huang, STAT3 as a central regulator of tumor metastases, Curr. Mol. Med. 9 (2009) 626-633.

[241] J. Gotzmann, A.N. Fischer, M. Zojer, M. Mikula, V. Proell, H. Huber, M. Jechlinger, T. Waerner, A. Weith, H. Beug, W. Mikulits, A crucial function of PDGF in TGF-beta-mediated cancer progression of hepatocytes, Oncogene 25 (2006) 3170-3185.

[242] A.N. Fischer, E. Fuchs, M. Mikula, H. Huber, H. Beug, W. Mikulits, PDGF essentially links TGF-beta signaling to nuclear beta-catenin accumulation in hepatocellular carcinoma progression, Oncogene 26 (2007) 3395-3405.

[243] J.S. Campbell, S.D. Hughes, D.G. Gilbertson, T.E. Palmer, M.S. Holdren, A.C. Haran, M.M. Odell, R.L. Bauer, H.P. Ren, H.S. Haugen, M.M. Yeh, N. Fausto, Platelet-derived growth factor $\mathrm{C}$ induces liver fibrosis, steatosis, and hepatocellular carcinoma, Proc. Natl. Acad. Sci. U. S. A. 102 (2005) 3389-3394.

[244] P. Czochra, B. Klopcic, E. Meyer, J. Herkel, J.F. Garcia-Lazaro, F. Thieringer, P. Schirmacher, S. Biesterfeld, P.R. Galle, A.W. Lohse, S. Kanzler, Liver fibrosis induced by hepatic overexpression of PDGF-B in transgenic mice, J. Hepatol. 45 (2006) 419-428.

[245] E. Borkham-Kamphorst, C.R. van Roeyen, T. Ostendorf, J. Floege, A.M. Gressner, R. Weiskirchen, Pro-fibrogenic potential of PDGF-D in liver fibrosis, J. Hepatol. 46 (2007) $1064-1074$.

[246] S.L. Friedman, Mechanisms of hepatic fibrogenesis, Gastroenterology 134 (2008) $1655-1669$.

[247] M. Debidda, L. Wang, H. Zang, V. Poli, Y. Zheng, A role of STAT3 in Rho GTPase-regulated cell migration and proliferation, J. Biol. Chem. 280 (2005) $17275-17285$

[248] T.R. Faruqi, D. Gomez, X.R. Bustelo, D. Bar-Sagi, N.C. Reich, Rac1 mediates STAT3 activation by autocrine IL-6, Proc. Natl. Acad. Sci. U. S. A. 98 (2001) 9014-9019.

[249] S. Pelletier, F. Duhamel, P. Coulombe, M.R. Popoff, S. Meloche, Rho family GTPases are required for activation of Jak/STAT signaling by G protein-coupled receptors, Mol. Cell. Biol. 23 (2003) 1316-1333.

[250] A. Hall, Rho GTPases and the actin cytoskeleton, Science 279 (1998) 509-514.

[251] Q.H. Ye, L.X. Qin, M. Forgues, P. He, J.W. Kim, A.C. Peng, R. Simon, Y. Li, A.I. Robles, Y. Chen, Z.C. Ma, Z.Q. Wu, S.L. Ye, Y.K. Liu, Z.Y. Tang, X.W. Wang, Predicting hepatitis B virus-positive metastatic hepatocellular carcinomas using gene expression profiling and supervised machine learning, Nat. Med. 9 (2003) 416-423.

[252] J. Dien, H.M. Amin, N. Chiu, W. Wong, C. Frantz, B. Chiu, J.R. Mackey, R. Lai, Signal transducers and activators of transcription-3 up-regulates tissue inhibitor of metalloproteinase-1 expression and decreases invasiveness of breast cancer, Am. J. Pathol. 169 (2006) 633-642.

[253] I.C. Gaemers, H.L. Vos, H.H. Volders, S.W. van der Valk, J. Hilkens, A stat-responsive element in the promoter of the episialin/MUC1 gene is involved in its overexpression in carcinoma cells, J. Biol. Chem. 276 (2001) 6191-6199.

[254] Y. Liu, A. Liu, H. Li, C. Li, J. Lin, Celecoxib inhibits interleukin-6/interleukin-6 receptor-induced JAK2/STAT3 phosphorylation in human hepatocellular carcinoma cells, Cancer Prev. Res. (Phila.) 4 (2011) 1296-1305

[255] Y. Liu, A. Liu, Z. Xu, W. Yu, H. Wang, C. Li, J. Lin, XZH-5 inhibits STAT3 phosphorylation and causes apoptosis in human hepatocellular carcinoma cells, Apoptosis 16 (2011) 502-510.

[256] Y. Liu, J. Fuchs, C. Li, J. Lin, IL-6, a risk factor for hepatocellular carcinoma: FLLL32 inhibits IL-6-induced STAT3 phosphorylation in human hepatocellular cancer cells, Cell Cycle 9 (2010) 3423-3427.

[257] C. Moser, S.A. Lang, A. Mori, C. Hellerbrand, H.J. Schlitt, E.K. Geissler, W.E. Fogler, O. Stoeltzing, ENMD-1198, a novel tubulin-binding agent reduces HIF-1alpha and STAT3 activity in human hepatocellular carcinoma(HCC) cells, and inhibits growth and vascularization in vivo, BMC Cancer 8 (2008) 206.

[258] S. Fletcher, J. Turkson, P.T. Gunning, Molecular approaches towards the inhibition of the signal transducer and activator of transcription 3 (Stat3) protein, ChemMedChem 3 (2008) 1159-1168.

[259] F. Li, P.P. Fernandez, P. Rajendran, K.M. Hui, G. Sethi, Diosgenin, a steroidal saponin, inhibits STAT3 signaling pathway leading to suppression of proliferation and chemosensitization of human hepatocellular carcinoma cells, Cancer Lett. 292 (2010) 197-207.
[260] S.M. Tan, F. Li, P. Rajendran, A.P. Kumar, K.M. Hui, G. Sethi, Identification of beta-escin as a novel inhibitor of signal transducer and activator of transcription 3/Janus-activated kinase 2 signaling pathway that suppresses proliferation and induces apoptosis in human hepatocellular carcinoma cells, J. Pharmacol. Exp. Ther. 334 (2010) 285-293.

[261] P. Rajendran, T.H. Ong, L. Chen, F. Li, M.K. Shanmugam, S. Vali, T. Abbasi, S Kapoor, A. Sharma, A.P. Kumar, K.M. Hui, G. Sethi, Suppression of signal transducer and activator of transcription 3 activation by butein inhibits growth of human hepatocellular carcinoma in vivo, Clin. Cancer Res. 17 (2011) $1425-1439$.

262] P. Rajendran, F. Li, K.A. Manu, M.K. Shanmugam, S.Y. Loo, A.P. Kumar, G. Sethi, gamma-Tocotrienol is a novel inhibitor of constitutive and inducible STAT3 signalling pathway in human hepatocellular carcinoma: potential role as an antiproliferative, pro-apoptotic and chemosensitizing agent, Br. J. Pharmacol. 163 (2011) 283-298.

[263] P. Rajendran, F. Li, M.K. Shanmugam, S. Vali, T. Abbasi, S. Kapoor, K.S. Ahn, A.P. Kumar, G. Sethi, Honokiol inhibits signal transducer and activator of transcription-3 signaling, proliferation, and survival of hepatocellular carcinoma cells via the protein tyrosine phosphatase SHP-1. J. Cell. Physiol. 227 (2012) 2184-2195.

[264] P. Rajendran, F. Li, M.K. Shanmugam, R. Kannaiyan, J.N. Goh, K.F. Wong, W. Wang, E. Khin, V. Tergaonkar, A.P. Kumar, J.M. Luk, G. Sethi, Celastrol suppresses growth and induces apoptosis of human hepatocellular carcinoma through the modulation of STAT3/JAK2 signaling cascade in vitro and in vivo, Cancer Prev. Res. (Phila.) 5 (2012) 631-643.

[265] K.F. Chen, J.C. Su, C.Y. Liu, J.W. Huang, K.C. Chen, W.L. Chen, W.T. Tai, C.W. Shiau A novel obatoclax derivative, SC-2001, induces apoptosis in hepatocellular carcinoma cells through SHP-1-dependent STAT3 inactivation, Cancer Lett. 321 (2012) 27-35.

[266] F.M. Gu, Q.L. Li, Q. Gao, J.H. Jiang, X.Y. Huang, J.F. Pan, J. Fan, J. Zhou, Sorafenib inhibits growth and metastasis of hepatocellular carcinoma by blocking STAT3, World J. Gastroenterol. 17 (2011) 3922-3932.

267] W.T. Tai, A.L. Cheng, C.W. Shiau, C.Y. Liu, C.H. Ko, M.W. Lin, P.J. Chen, K.F. Chen, Dovitinib induces apoptosis and overcomes sorafenib resistance in hepatocellular carcinoma through SHP-1-mediated inhibition of STAT3, Mol. Cancer Ther. 11 (2012) 452-463.

[268] B.D. Page, D.P. Ball, P.T. Gunning, Signal transducer and activator of transcription 3 inhibitors: a patent review, Expert Opin. Ther. Pat. 21 (2011) 65-83.

[269] B.B. Aggarwal, S. Shishodia, S.K. Sandur, M.K. Pandey, G. Sethi, Inflammation and cancer: how hot is the link? Biochem. Pharmacol. 72 (2006) 1605-1621.

[270] M. Weidler, J. Rether, T. Anke, G. Erkel, Inhibition of interleukin-6 signaling and Stat3 activation by a new class of bioactive cyclopentenone derivatives, Biochem. Biophys. Res. Commun. 276 (2000) 447-453.

[271] J. Schust, B. Sperl, A. Hollis, T.U. Mayer, T. Berg, Stattic: a small-molecule inhibitor of STAT3 activation and dimerization, Chem. Biol. 13 (2006) 1235-1242.

[272] D. Carlisi, A. D'Anneo, L. Angileri, M. Lauricella, S. Emanuele, A. Santulli, R. Vento, G. Tesoriere, Parthenolide sensitizes hepatocellular carcinoma cells to TRAIL by inducing the expression of death receptors through inhibition of STAT3 activation, J. Cell. Physiol. 226 (2011) 1632-1641.

[273] A. Lavecchia, C. Di Giovanni, E. Novellino, STAT-3 inhibitors: state of the art and new horizons for cancer treatment, Curr. Med. Chem. 18 (2011) 2359-2375.

[274] Z. Duan, J.E. Bradner, E. Greenberg, R. Levine, R. Foster, J. Mahoney, M.V. Seiden, SD-1029 inhibits signal transducer and activator of transcription 3 nuclear translocation, Clin. Cancer Res. 12 (2006) 6844-6852.

[275] W.T. Tai, A.L. Cheng, C.W. Shiau, H.P. Huang, J.W. Huang, P.J. Chen, K.F. Chen, Signal transducer and activator of transcription 3 is a major kinase-independent target of sorafenib in hepatocellular carcinoma, J. Hepatol. 55 (2011) 1041-1048.

276] K.F. Chen, W.T. Tai, T.H. Liu, H.P. Huang, Y.C. Lin, C.W. Shiau, P.K. Li, P.J. Chen, A.L. Cheng, Sorafenib overcomes TRAIL resistance of hepatocellular carcinoma cells through the inhibition of STAT3, Clin. Cancer Res. 16 (2010) 5189-5199.

[277] C. Won, C.S. Lee, J.K. Lee, T.J. Kim, K.H. Lee, Y.M. Yang, Y.N. Kim, S.K. Ye, M.H. Chung, CADPE suppresses cyclin D1 expression in hepatocellular carcinoma by blocking IL-6-induced STAT3 activation, Anticancer. Res. 30 (2010) 481-488.

[278] Y. Wang, X. Ma, S. Yan, S. Shen, H. Zhu, Y. Gu, H. Wang, G. Qin, Q. Yu, 17-hydroxy-jolkinolide B inhibits signal transducers and activators of transcription 3 signaling by covalently cross-linking Janus kinases and induces apoptosis of human cancer cells, Cancer Res. 69 (2009) 7302-7310.

[279] S. Metz, M. Wiesinger, M. Vogt, H. Lauks, G. Schmalzing, P.C. Heinrich, G Muller-Newen, Characterization of the interleukin (IL)-6 inhibitor IL-6-RFP. fused receptor domains act as high affinity cytokine-binding proteins, J. Biol. Chem. 282 (2007) 1238-1248.

280] C.K. Lau, ZF. Yang, S.P. Lam, C.T. Lam, P. Ngai, K.H. Tam, R.T. Poon, S.T. Fan, Inhibition of Stat3 activity by YC-1 enhances chemo-sensitivity in hepatocellular carcinoma, Cancer Biol. Ther. 6 (2007) 1900-1907.

281] S.R. Choudhari, M.A. Khan, G. Harris, D. Picker, G.S. Jacob, T. Block, K. Shailubhai, Deactivation of Akt and STAT3 signaling promotes apoptosis, inhibits proliferation, and enhances the sensitivity of hepatocellular carcinoma cells to an anticancer agent, Atiprimod, Mol. Cancer Ther. 6 (2007) 112-121.

[282] K. Selvendiran, H. Koga, T. Ueno, T. Yoshida, M. Maeyama, T. Torimura, H. Yano, M. Kojiro, M. Sata, Luteolin promotes degradation in signal transducer and activator of transcription 3 in human hepatoma cells: an implication for the antitumor potential of flavonoids, Cancer Res. 66 (2006) 4826-4834.

[283] C. Arnaud, F. Burger, S. Steffens, N.R. Veillard, T.H. Nguyen, D. Trono, F. Mach, Statins reduce interleukin-6-induced C-reactive protein in human hepatocytes: new evidence for direct antiinflammatory effects of statins, Arterioscler. Thromb. Vasc. Biol. 25 (2005) 1231-1236. 